\title{
DEEP EUTECTIC SOLVENT PRETREATMENT FOR ENHANCING BIOCHEMICAL CONVERSION OF SWITCHGRASS
}

\author{
A Thesis \\ presented to
}

The Faculty of the Graduate School

at the University of Missouri-Columbia

In Partial Fulfillment

of the Requirements for the Degree

Master of Science

by

MARYAM AL AMERI

Dr. Caixia Wan, Thesis Supervisor

July 2017 
(C) Copyright by Maryam Al Ameri 2017

All Rights Reserved 
The undersigned, appointed by the dean of the Graduate School, have examined the thesis entitled

\section{DEEP EUTECTIC SOLVENT PRETREATMENT FOR ENHANCING BIOCHEMICAL CONVERSION OF SWITCHGRASS}

presented by Maryam Al Ameri, a candidate for the degree of Master of Science, and hereby certify that, in their opinion, it is worthy of acceptance.

Dr. Caixia Wan

Bioengineering program

Dr. William Jacoby

Bioengineering program

Dr. Karl Hammond

Chemical Engineering program 
I would like to dedicate this thesis to my loving husband, Hussein Al Jashamie, and my lovely son and daughter, Ibrahim Hussein and Sarah Hussein. I also would like to express my gratitude to my parents, Tareq Hasan and Zahra Hussein. They have supported me continuously throughout my entire life. I love all of you. 


\section{Acknowledgments}

I would like to express my gratitude to my adviser Dr. Caixia Wan for all her support and encouragement, guidance, advice, and patience throughout my graduate study. I would not be able to finish my research without her supervision.

I also would thank Dr. William Jacoby and Dr. Karl Hammond for their time and efforts serving on my graduate committee and providing valuable advice in my research project and thesis.

Many thanks go to my lab mates and friends, especially Zhu Chen for all the help and suggestions to my research project. I also thank Lakdas Fernando in the Food Science department for his help with HPLC analysis. Also, thanks go to my friend Tammy Carmichael for her motivation.

Finally, I would like to thank my husband Hussein Al Jashamie for his support and motivation. I would not have finished my graduate study smoothly without his support. I would also like to thank my parents, Tareq Hasan and Zahra Hussein, for their prayer and motivation throughout my graduate study and my whole life. 


\section{Table of Contents}

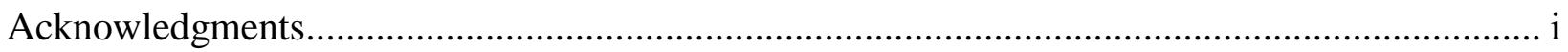

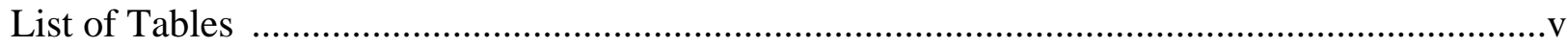

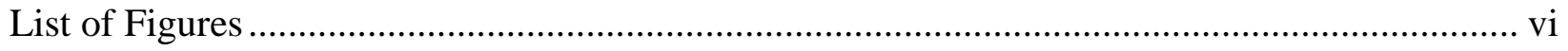

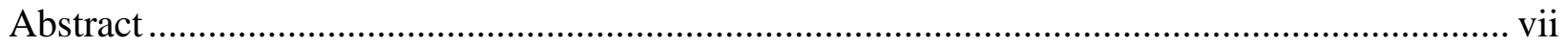

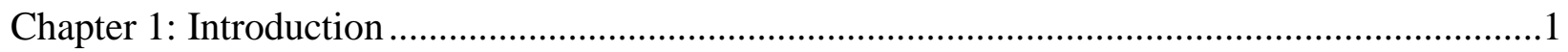

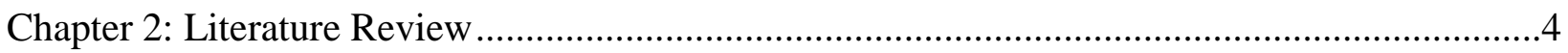

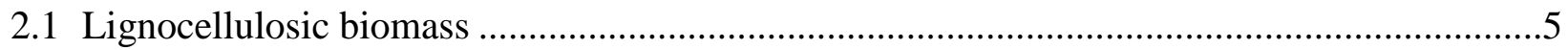

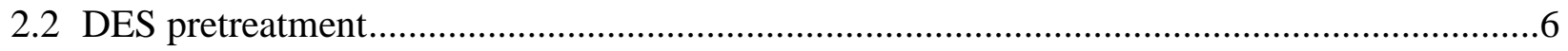

2.3 Enzymatic hydrolysis and detoxification of enzymatic hydrolysate .................................13

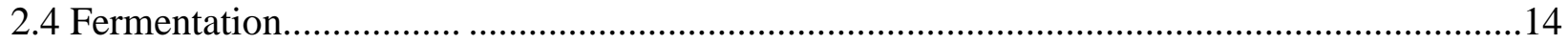

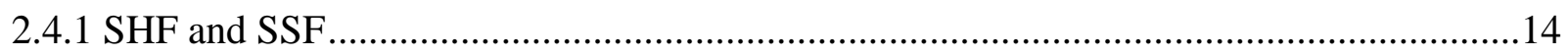

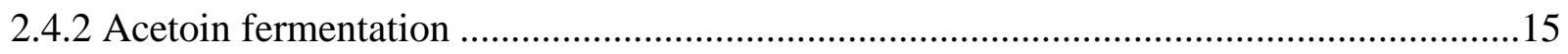

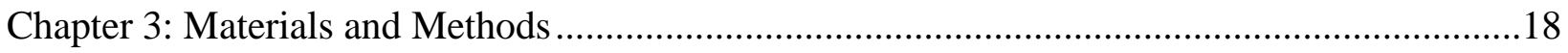

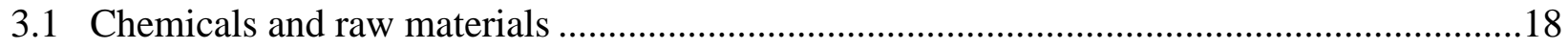

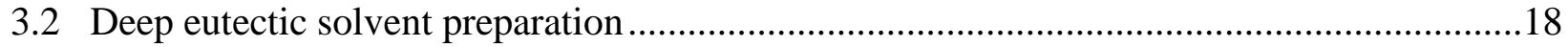

3.3 DES pretreatment of lignocellulosic biomass ............................................................. 19

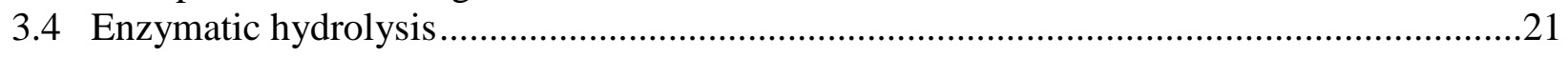

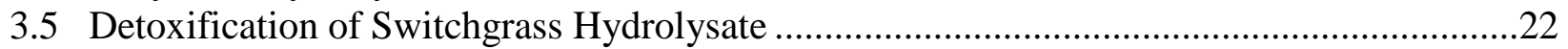

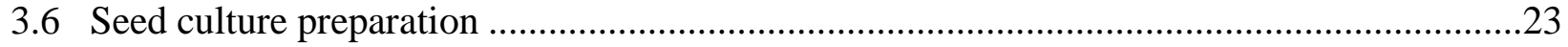

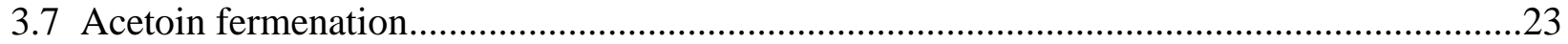

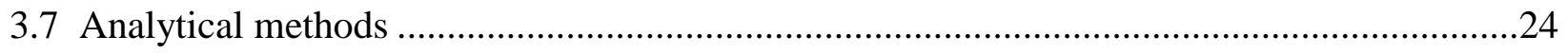

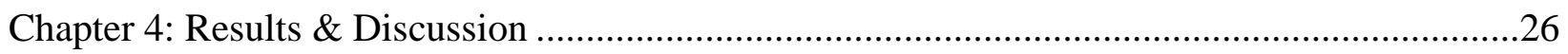

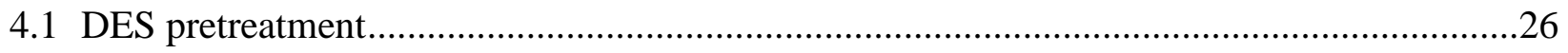

4.1.1 Composition of raw and pretreated switchgrass ............................................26

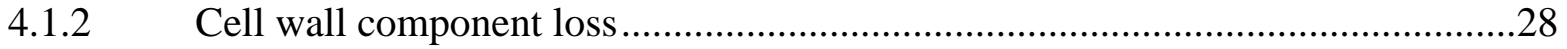

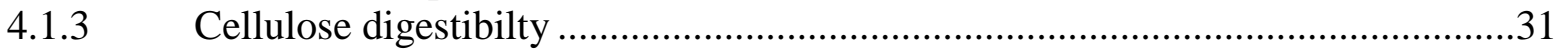

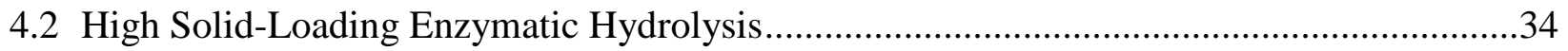

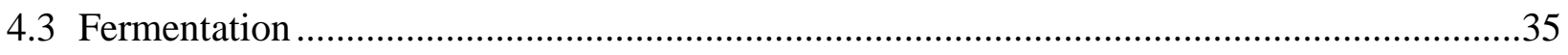

4.3.1 Effect of initial $\mathrm{pH}$ on B. licheniformis growth and acetoin production ..............35

4.3.2 Effects of temperature on $B$. licheniformis growth and acetoin production ..........36

4.3.3 Effects of initial glucose concentration on the main product distribution............38 
4.3.4 Acetoin fermenation using pretreated switchgrass ............................................

Chapter 5: Conclusion and Future Work …………………........................................................4

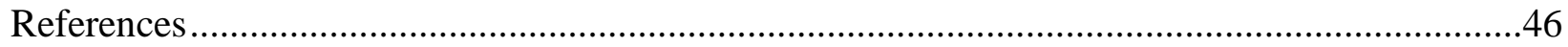




\section{List of Tables}

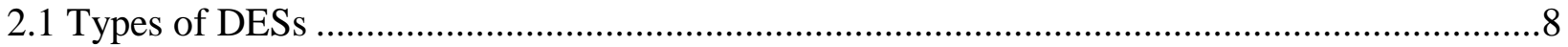

2.2 Studies of DES pretreatment on different lignocellulosic biomass. ........................................12

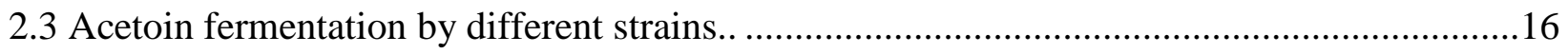

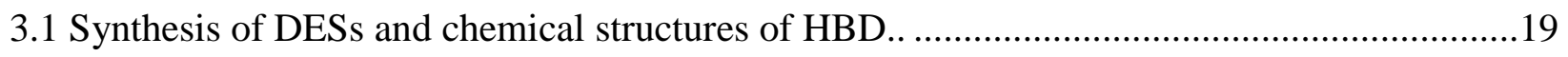

4.1 Effects of DES pretreatment on the composition of switchgrass ..........................................27

4.2 Sugars production from high solid-loading enzymatic hydrolysis ...........................................35

4.3 Effect of initial $\mathrm{pH}$ of fermentation media on acetoin production...........................................36

4.4 Effect of fermentation temperature on acetoin production.......................................................37 


\section{List of Figures}

1.1 Diagram of DES pretreatment and biochemical conversion of switchgrass for acetoin production

2.1 Production of biofuels and chemicals from lignocellulosic biomass via biochemical conversion....

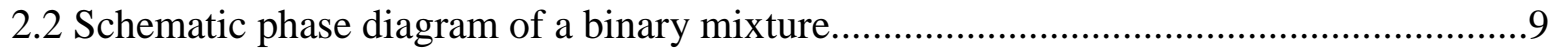

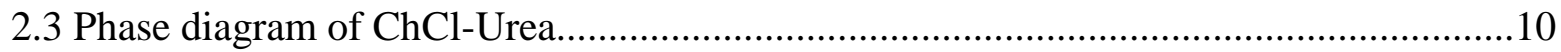

2.4 Metabolic pathway of acetoin production by B. licheniformis WX-02 .........................17

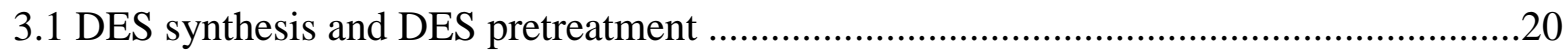

4.1 Solid recovery after DES pretreatment ..............................................................29

4.2 Cell wall component loss in response to DES pretreatment. ..........................................30

4.3 Effects of DES pretreatment on switchgrass digestibility (a) glucose yields, (b) xylose

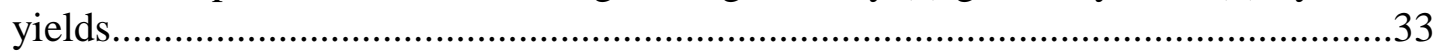

4.4 Effects of initial $\mathrm{pH}$ on B.licheniformis growth and acetoin production.........................36

4.5 Effects of fermentation temperature on B. licheniformis growth and acetoin

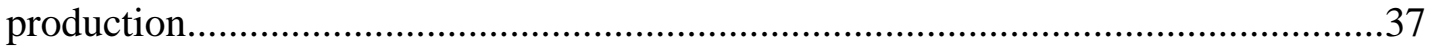

4.6 Main production distribution in response to initial glucose concentration:(a) $50 \mathrm{~g} / \mathrm{L}$ initial glucose concentration, and (b) $80 \mathrm{~g} / \mathrm{L}$ initial glucose concentration

4.7 $\mathrm{T}$ The effect of overliming on sugar concentration

4.8 Growth of B. licheniformis in fermentation media containing pure or biomass hydrolysate......

4.9 Acetoin production and glucose consumption by $B$. licheniformis using pretreated biomass.

4.10 Growth of B. licheniformis in (a) control and (b) SSF 


\begin{abstract}
In this study, green solvent-based pretreatment was developed for improving the conversion of switchgrass to acetoin. Deep eutectic solvents (DESs), comprising choline chloride $(\mathrm{ChCl})$ as a hydrogen-bond acceptor $(\mathrm{HBA})$ and various chemical as a hydrogen-bond donor (HBD), were used to pretreat switchgrass. Different HBD groups, including polyalcohol, amid, diazole, and carboxylic acid, were used to synthesize DESs. The DESs using ChCl-formic acid and ChCl-lactic acid-acetic acid showed excellent performance in enhancing switchgrass digestibility. The obtained hydrolysate was successfully detoxified by using overliming detoxification, which was further used for acetoin fermentation by Bacillus licheniformis (NRRL B-642). The yield and titer of the produced acetoin were $0.377 \mathrm{~g} / \mathrm{g}$ and $19.6 \mathrm{~g} / \mathrm{L}$, respectively. Our research demonstrates that DES pretreatment is an effective method for reducing biomass recalcitrance and improving the conversion of biomass into chemicals.
\end{abstract}




\section{Chapter 1 Introduction}

Climate change and extensive use of fossil fuels have been driving researchers worldwide to explore alternative sources of energy and chemicals. Renewable sources could be considered be green and abundant alternatives to fossil fuel. Lignocellulosic biomass, a representative renewable source, is widely available and does not compete with food/feed supply. It is composed mainly of $15-25 \%$ lignin, $15-25 \%$ hemicellulose, and $30-50 \%$ cellulose, which is a good source of fermentable sugars and aromatic compounds. Switchgrass is a dedicated energy crop that can grow on marginal land and has low requirements for nutrients and water. Great efforts have been made to convert switchgrass to a variety of industrially-important products via different routes, such as physical pretreatment, biochemical pretreatment, chemical pretreatment, and a combination of them. Biochemical conversion of lignocellulosic biomass involves the use of microorganisms and enzymes as the biocatalysis, but often requires the pretreatment to reduce the recalcitrance nature of lignocellulose and to make the sugars accessible. Many studies have been done to develop costeffective and environmentally friendly pretreatment technologies. Deep eutectic solvent (DES) pretreatment is an emerging pretreatment method that can efficiently fractionate biomass. DES is a mixture of two or three compounds which one of them hydrogen bond acceptor (HBA) and the another one is hydrogen bond donor (HBD). As HBA, quandary ammonium salt such as choline chloride has been used mainly to synthesis DESs. However, many compounds have been used as HBDs (e.g. polyalcohol, acids, amides, etc.). In addition, DESs are cheap, easy to synthesize, biodegradable, which makes this category of solvent a good candidate for solvent-based pretreatment. 
Acetoin is a versatile platform chemical that can be produced from either petroleum-based or renewable sources. Acetoin has broad applications in the food, cosmetics, and pharmaceuticals industries. While fermentative production of acetoin is already commercialized, it still relies on the use of pure sugar or starch as the carbon sources for microbial conversion. It is thus worth exploring the technically feasible and economically viable route for converting lignocellulose biomass to acetoin. Acetoin is produced by using different bacterial strains such as Bacillus licheniformis which represents one of the top ten acetoin producers.

The overall goal of this study was to develop a green DES pretreatment process to enhance the conversion of switchgrass to acetoin as shown in Figure 1.1. To achieve this goal, the specific objectives of this study were to:

1) Synthesize various ChCl-based DESs and screen for the best performing DESs for the pretreatment of switchgrass by evaluating the change in chemical composition and cellulose digestibility of the pretreated switchgrass.

2) Develop high solid-loading enzymatic hydrolysis for generating glucose-rich hydrolysate for fermentation, and also investigate the toxicity of the pretreated biomass to the acetoinproducing bacterial strain Bacillus licheniformis (NRRL B-642).

3) Develop and optimize the fermentation processes for acetoin production by $B$. Licheniformis using DES-pretreated biomass as the carbon sources via separate hydrolysis and fermentation (SHF) and simultaneous scarification and fermentation (SSF). 


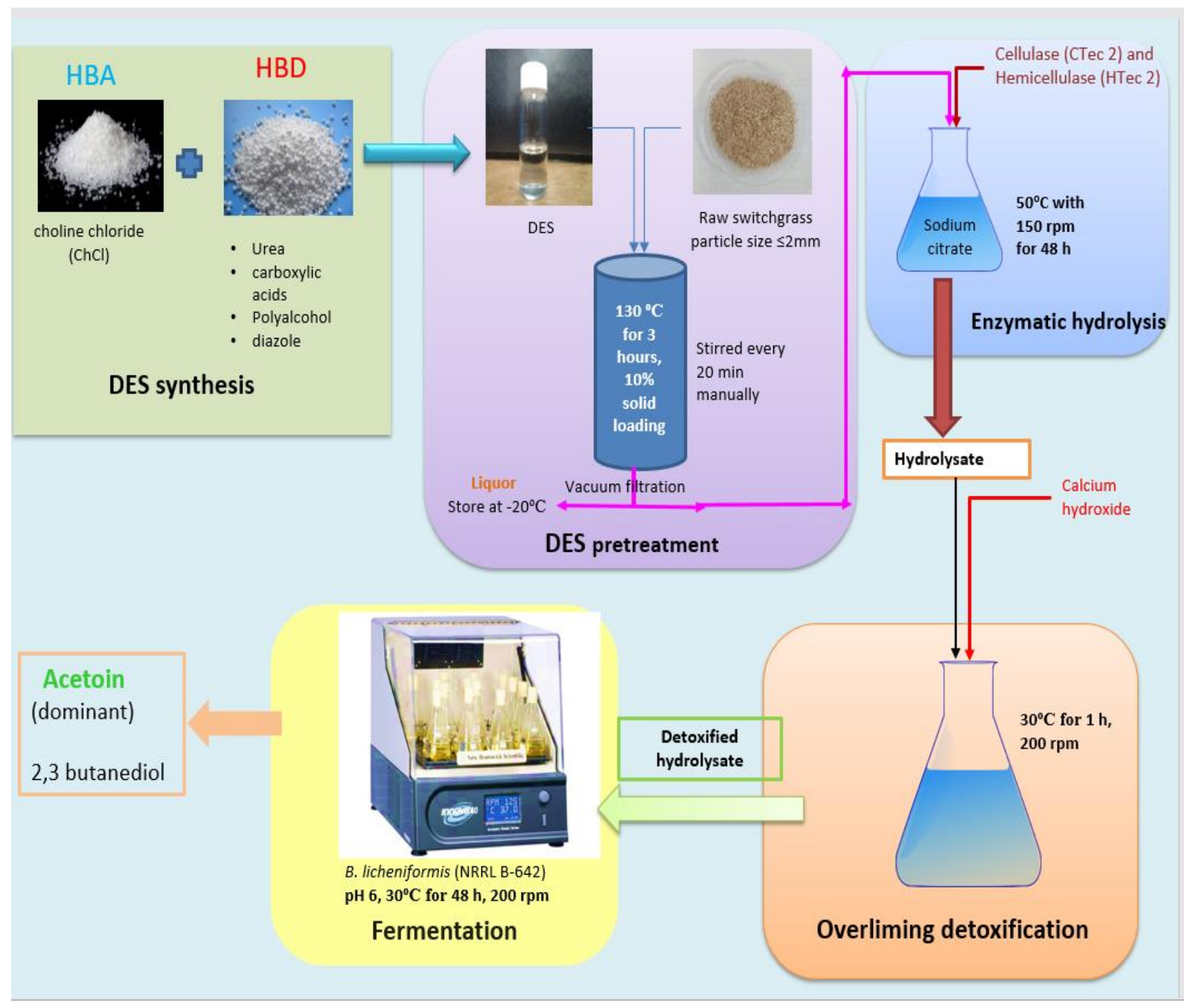

Figure 1.1 Schematic diagram of DES pretreatment and biochemical conversion of switchgrass into acetoin. 


\section{Chapter 2 Literature Review}

Escalating environmental issues and changes in the climate have been a big concern since the last century. More and more energy is being consumed for electricity, transportation, heat, and other requirements. Fossil fuels have been used extensively to provide the needed energy for most human activities. According to the Institute for Energy Research (IER) in 2016, 95\% of transportation fuel in the US come from fossil fuels. The combustion of fossil fuels emits greenhouse gases (GHG) such as carbon dioxide into atmosphere. In addition, fossil fuels are nonrenewable energy source. For these reasons, renewable, safe, and cheap alternative sources need to be explored.

One such example is lignocellulosic biomass which has been used as a feedstock for biofuel production. It represents the largest organic source in the earth, and is cheap, non-edible and rich in polysaccharides (Alvira, Tomás-Pejó et al. 2010, Mussatto 2016). Also, using it as a renewable source of energy not only improves long-term energy security, but also reduces GHG and waste sources (Prasad, Sotenko et al. 2016). Lignocellulosic materials are classified into three groups: agricultural residues (e.g., wheat straw, sugarcane bagasse, corn stover), dedicated energy crops (e.g., Miscanthus, timothy grass, energy tobacco, switchgrass), and woody materials (e.g., forest arising, stumps, woody stem). Producing biofuel or chemicals based on biochemical conversion involves three main processes: pretreatment, enzymatic hydrolysis, and fermentation as shown in Figure 2.1. 

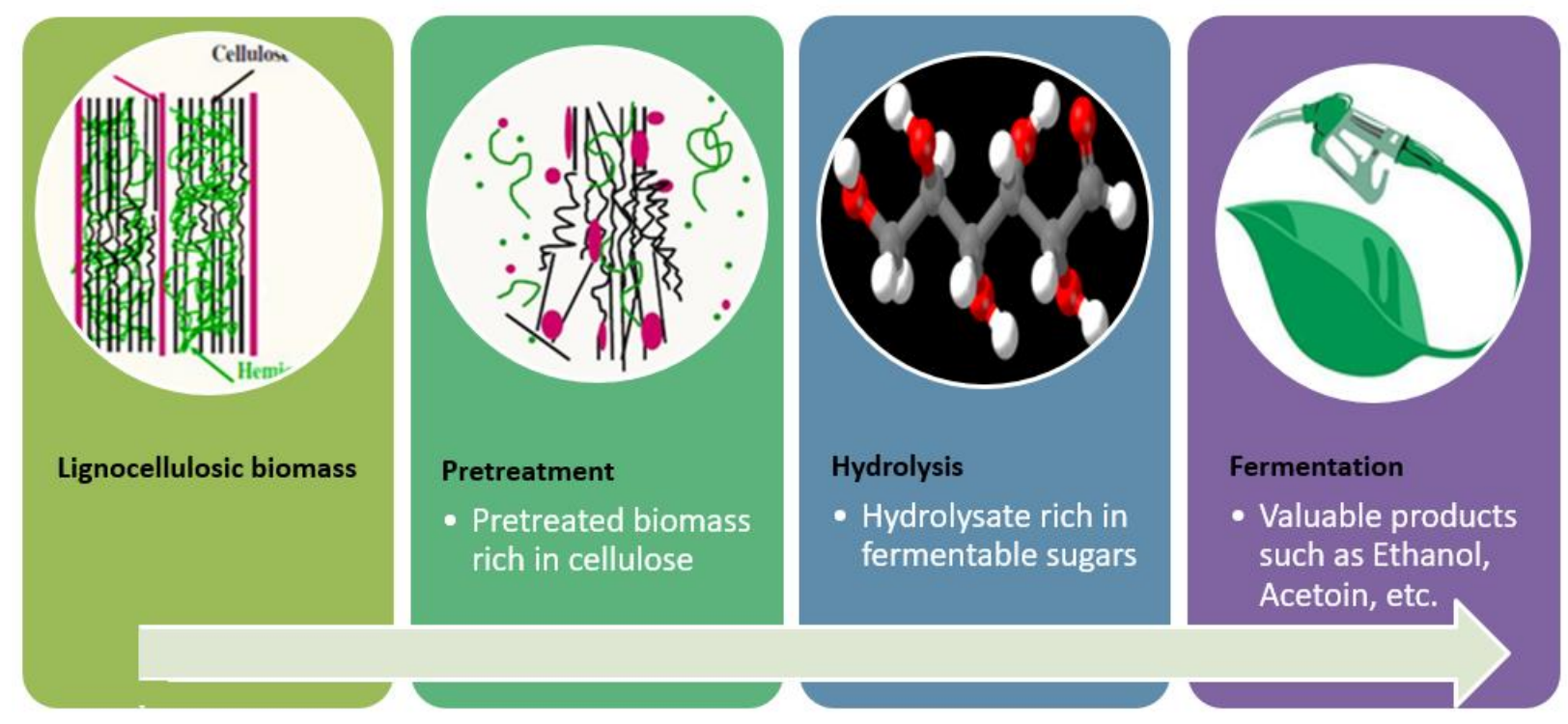

Figure 2.1 Production of biofuels and chemicals from lignocellulosic biomass via biochemical conversion. (Mosier, Wyman et al. 2005)

\subsection{Lignocellulosic biomass}

Lignocellulosic biomass is composed of three major components: lignin, hemicellulose, and cellulose (Murzin 2012). Cellulose and hemicellulose constitute around 70\% of lignocellulosic biomass (Limayem and Ricke 2012).Cellulose, a linear polymer of glucose, is bound with hemicellulose and both of them are surrounded by lignin. Hemicellulose is the second most abundant polymer in lignocellulose. It is composed of pentoses ( $\beta$-D-xylose, $\alpha$-L-arabinose), hexoses ( $\beta$-D-mannose, $\beta$-D-glucose, $\alpha$-D-galactose) and/or uronic acids ( $\alpha$-D-glucuronic, $\alpha$-D-4O-methylgalacturonic and $\alpha$-D-galacturonic acids) (Gírio, Fonseca et al. 2010). Hemicellulose has varying chemical compositions depending on the nature and sources of the feedstock. For example, hardwood hemicelluloses mainly consist of xylan while in softwood hemicelluloses, glucomannan is the backbone (Saha 2003, Limayem and Ricke 2012). Hemicelluloses interlink the cellulose fibrils, which make the cellulose resistant to decomposition. Thus, the removal of hemicellulose 
can expose cellulose and make cellulose easy to be depolymerized (Saha 2003, Bajpai 2016). Similar to cellulose, hemicellulose is another source of fermentable sugars. Due to its amorphous and branched structures with short lateral chains, hemicelluloses are relatively easy to hydrolyze (Li, Fan et al. 2010). Multiple hemicellulases, such as endo- $\beta$-1,4-xylanase, and $\beta$-xylosidase, are often required to hydrolyze hemicellulose due to its heterogeneous chemical properties (Saha 2003).

Lignin is an irregular and heterogeneous polymer of phenylpropaniod units (mainly coniery alcohol, sinapyl alcohol, and p-cumary alcohol) which are bound with each other by various linkages, such as $\beta$-O-aryl ether and resistant C-C bounds (Stöcker 2008, Mussatto 2016). Lignin is responsible for the rigidity and physical strength of the cell wall of biomass, making the plant more resistant to enzymatic and microbial attack. It also provides the plant with a hydrophobic vascular system for the transportation of water and solutes (Alonso, Bond et al. 2010, Mussatto 2016).

\subsection{DES pretreatment}

The recalcitrance of lignocellulosic biomass makes hydrolysis of cellulose a challenge (Mussatto, 2016). Pretreatment is a process that aims to make cellulose easier to hydrolyze by either acids or enzymes by the following: (1) removing the lignin and hemicellulose fractions, (2) reducing the crystallinity of cellulose, and (3) increasing the porosity of the lignocellulosic materials. Many studies have been done to develop an efficient pretreatment process that can enhance the release of sugars and minimize the formation of byproducts or any toxic compounds (Kumar, Barrett et al. 2009). Pretreatment methods can be classified into different categories: physical, chemical, biological, and a combination of some of these pretreatment methods (Alvira, Tomás-Pejó et al. 2010). Each method has its own advantages and disadvantages. Chemical 
pretreatment is still the leading method adopted in bio-refinery industry. Chemical pretreatment uses chemicals to remove undesirable fractions (lignin and hemicellulose) and thus makes cellulose become more accessible to enzymes. Deeply investigated pretreatment processes include alkaline, wet oxidation, acid, green solvent, and ozonolysis pretreatments (Alvira, Tomás-Pejó et al. 2010, Brodeur, Yau et al. 2011).

In the past twenty years, novel green solvents called ionic liquids (ILs) have gained researcher's attention and there are numerous publications describing their applications and mechanisms. ILs are salts composed of ionic species, organic cation and an organic/inorganic anion, with a melting point lower than $100^{\circ} \mathrm{C}$ and predominately in liquid form at ambient temperature (Kimon, Alan et al. 2011, Paiva, Craveiro et al. 2014, van Osch, Kollau et al. 2017). ILs are non-volatile, non-explosive, stable over a wide range of temperatures and reaction conditions. They also have high ionic conductivity, high thermal conductivity, and high dissolution capability toward many substrates (Kimon, Alan et al. 2011, Zhao and Baker 2013). In spite of all these advantages, ILs have poor biodegradability, biocompatibility, and sustainability and are often expensive and toxic (Zhang, Vigier et al. 2012, Paiva, Craveiro et al. 2014).

Deep eutectic solvents (DESs), analog to ILs, are cheaper, simpler to prepare and purify, non-toxic, safe, and the majority of them are biodegradable and biocompatible (Gorke, Srienc et al. 2008, Smith, Abbott et al. 2014, Wahlström, Hiltunen et al. 2016). DESs are the mixtures of quaternary ammonium salts as hydrogen bond acceptors (HBAs) and other chemicals as hydrogen bond donors (HBDs). They are a eutectic liquid with a melting point lower than that of their individual components (Zhang, Vigier et al. 2012). Choline chloride ( $\mathrm{ChCl}$ ) has been widely used as a quaternary ammonium salt for the synthesis of DESs because it has significant advantages over other quaternary ammonium salts. It is inexpensive, easy to synthesize, non-toxic, and 
biodegradable (Zhao and Baker 2013, Smith, Abbott et al. 2014). In terms of hydrogen bond donors, there are numerous choices, such as amides, amines, carboxylic acids, alcohols, and metal salts (Zhao and Baker 2013, Smith, Abbott et al. 2014). DESs can be divided into four groups based on a complexing agent as shown in Table 2.1.

Table 2.1 Types of DES*

\begin{tabular}{|c|c|c|c|c|}
\hline & Type & $\begin{array}{l}\text { Chemical } \\
\text { structure }\end{array}$ & Formula & \\
\hline I & $\begin{array}{l}\text { Quaternary ammonium salt }+ \text { metal } \\
\text { chloride a }\end{array}$ & $\mathrm{Cl}_{\mathrm{Cn}}^{\mathrm{Cl}}$ & $\mathrm{Cat}^{+} \mathrm{X}^{-} z M C l_{x}$ & $\begin{array}{l}\mathrm{M}=\mathrm{Zn}, \mathrm{Sn}, \\
\mathrm{Fe}, \mathrm{AL}, \mathrm{Ga}, \mathrm{In}\end{array}$ \\
\hline II & $\begin{array}{l}\text { Quaternary ammonium salt }+ \text { metal } \\
\text { chloride hydrate } b\end{array}$ & 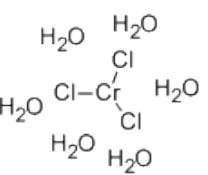 & $\mathrm{Cat}^{+} \mathrm{X}^{-} \mathrm{zMCl}_{x} \cdot y \mathrm{H}_{2} \mathrm{O}$ & $\begin{array}{l}\mathrm{M}=\mathrm{Cr}, \mathrm{Co} \\
\mathrm{Cu}, \mathrm{Ni}, \mathrm{Fe}\end{array}$ \\
\hline III & $\begin{array}{l}\text { Quaternary ammonium salt }+ \\
\text { hydrogen bond donor }\end{array}$ & & $\mathrm{Cat}^{+} \mathrm{X}^{-} \mathrm{zRZ}$ & $\begin{array}{l}\mathrm{Z}=\mathrm{CONH}_{2} \\
\mathrm{COOH}, \mathrm{OH}\end{array}$ \\
\hline IV & $\begin{array}{l}\text { Metal chloride hydrate }+ \text { hydrogen } \\
\text { bond donor } \mathrm{c}\end{array}$ & 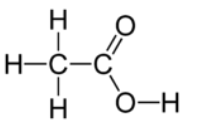 & $\begin{array}{r}M C l_{x}+R Z=M C l_{X-1}^{+} \cdot R Z \\
+M C l_{X+1}^{-}\end{array}$ & $\begin{array}{l}\mathrm{M}=\mathrm{Al}, \mathrm{Zn} \\
\mathrm{Z}=\mathrm{CONH}_{2} \\
\mathrm{OH}\end{array}$ \\
\hline
\end{tabular}

* This table was adapted from (Abbott, Barron et al. 2007, Zhao and Baker 2013, Smith, Abbott et al. 2014) a, b, c Chemical structure of example of metal chloride, metal chloride hydrate, and hydrogen bond donor, respectively.

DESs can be easily prepared by mixing their individual components at $100^{\circ} \mathrm{C}$ or below that (Abbott, Boothby et al. 2004, Francisco, van den Bruinhorst et al. 2012, Zhang, Vigier et al. 2012, Dai, van Spronsen et al. 2013, Francisco, van den Bruinhorst et al. 2013, Wahlström, Hiltunen et al. 2016, van Osch, Kollau et al. 2017). This method is called the heating under mixing method. There are also other DES preparation methods reported in literature. The vacuum evaporating method was used to synthesize DESs by dissolving their individual components in water and evaporating them under vacuum at $50^{\circ} \mathrm{C}$ by using a rotatory evaporator (Dai, van Spronsen et al. 2013, van Osch, Kollau et al. 2017). The grinding method is the most explored DES preparation method, which involves mixing and grinding two constituents at room temperature under a 
nitrogen flow until a homogenous liquid forms (Florindo, Oliveira et al. 2014, van Osch, Kollau et al. 2017).

In a eutectic system, chemical compounds usually in solid phase are melted at a lower temperature than the melting temperature of any individual compounds to form eutectic solvent. As depicted in Figure 2.2, a eutectic point depends on the melting temperatures and mixing ratios of HBA and HBD. For example, as shown in Figure 2.3, the melting point of choline chloride:urea $(\mathrm{ChCl}-\mathrm{U})$ at $1: 2$ molar ratio is $17^{\circ} \mathrm{C}$, much lower than those for $\mathrm{HBA}\left(\mathrm{ChCl}, 302^{\circ} \mathrm{C}\right)$ and for $\mathrm{HBA}$ (urea, $134^{\circ} \mathrm{C}$ ) as shown in Figure 2.3.

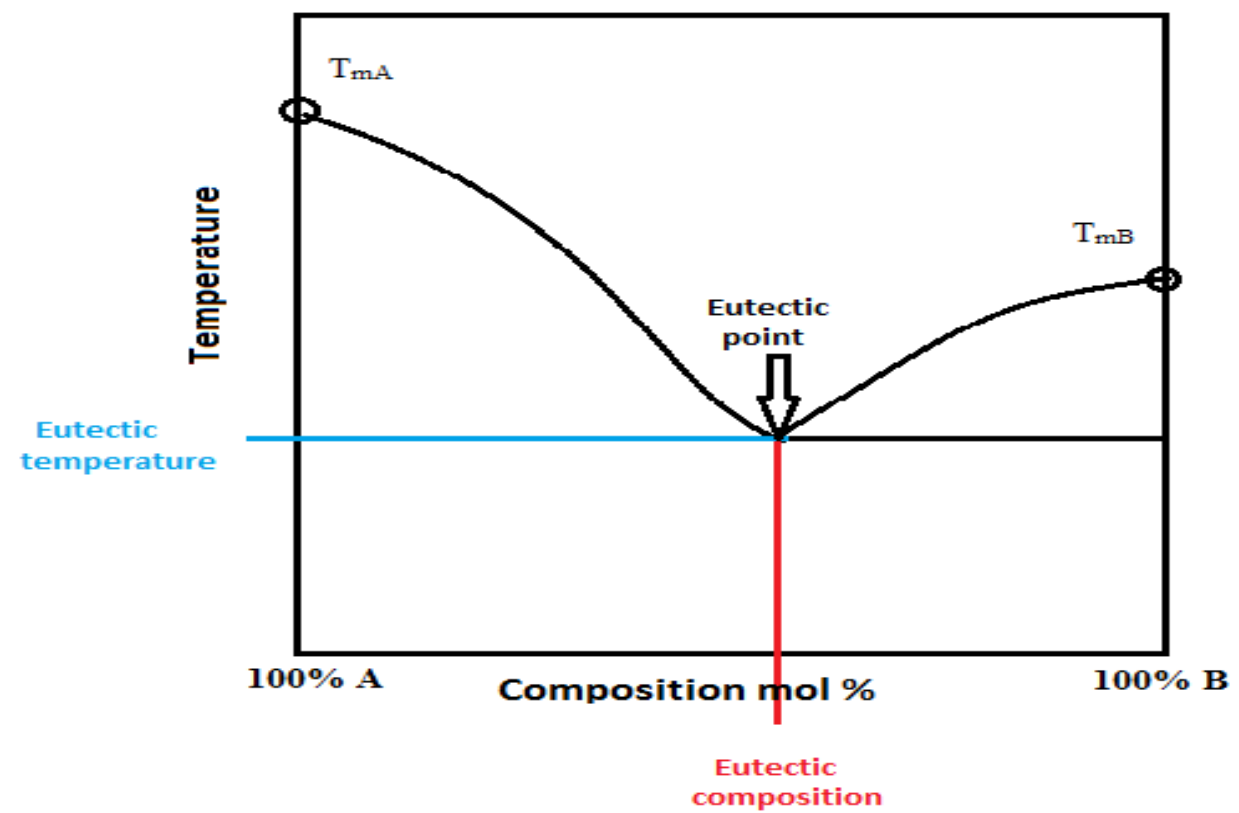

Figure 2.2 Schematic phase diagram of a binary mixture. $T_{\mathrm{mA}}$ and $T_{\mathrm{mB}}$ stand for melting temperatures of components $A$ and $B$, respectively. 


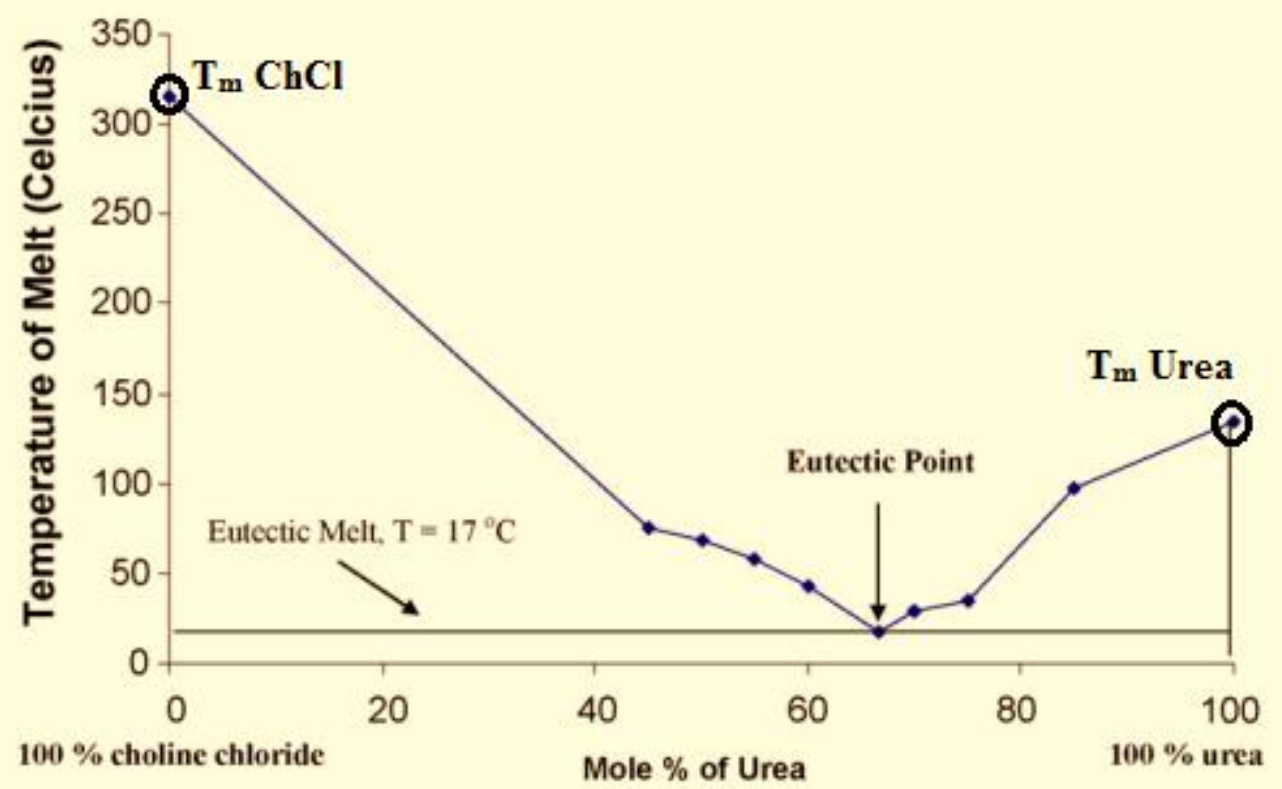

\section{Figure 2.3 Phase diagram of ChCl-Urea ( Diagram adapted from Morrison et al. (Morrison, Sun et al. 2009))}

DESs have been used in many applications such as dissolution and separation, catalysis, organic synthesis, electrochemistry, and preparation of materials (Zhang, Vigier et al. 2012). DESs pretreatment of biomass is an emerging solvent-based pretreatment. Table 2.2 summarizes the examples and effectiveness of DESs pretreatment. Francisco and coworkers first tested the ability of 26 DESs to dissolve starch, cellulose, and lignin. Their study concluded that most of the tested DESs can solubilize lignin but not cellulose. Choline chloride: lactic acid was shown to be most effective for lignin solubilization and lignin solubility increased with the increase in lactic acid content in DESs. However, the reverse trend was found with proline:malic acid DES pretreatment for which lignin solubility decreases with increased malic acid content. Proline:malic acid showed a higher ability to dissolve starch and cellulose. The significant selectivity of dissolving lignin from a combination of lignin and cellulose encouraged the researchers to do preliminary tests to check the solubility of raw wheat straw in choline chloride:lactic acid (1:2). This DES pretreatment 
led to significant lignin dissolution (Francisco, van den Bruinhorst et al. 2012). Procentese and coworkers pretreated corncob residues with choline chloride:glycerol, choline chloride: imidazole, and choline chloride:urea under specific conditions (Table 2.2). They found that choline chloride: imidazole can remove lignin efficiently and up to $80 \%$ of lignin of corncob residues was removed at $115^{\circ} \mathrm{C}$ (Procentese, Johnson et al. 2015). Kumar and coworkers also used choline chloride: lactic acid (1:2, 1:5 and 1:9) and betaine: lactic acid (1:2 and 1:5) to pretreat rice straw. Their study concluded that $\mathrm{ChCl}$-based DESs were more efficient than betaine-based DESs because $\mathrm{ChCl}$ has hydroxyl group in its structure, and $\mathrm{ChCl}$ :lactic acid (1:5) removed 60\% of the total lignin content of rice straw (Kumar, Parikh et al. 2016). 
Table 2.2 Studies of DES pretreatment on different types of lignocellulosic biomass.

\begin{tabular}{|c|c|c|c|c|c|c|c|c|c|}
\hline Biomass & $\begin{array}{l}\begin{array}{l}\text { Particle } \\
\text { size } \\
(\mathbf{m m})\end{array} \\
\end{array}$ & & DESs & $\begin{array}{l}\text { Molar Ratio } \\
\text { (HBA:HBD) }\end{array}$ & $\begin{array}{l}\begin{array}{l}\text { solid } \\
\text { loading } \\
\text { (wt\%) }\end{array} \\
\end{array}$ & $\begin{array}{l}\text { Time } \\
\text { (h) }\end{array}$ & $\begin{array}{l}\text { Tempura } \\
\left({ }^{\circ} \mathrm{C}\right)\end{array}$ & Effectiveness & Ref. \\
\hline \multirow[t]{2}{*}{ rice straw } & \multirow[t]{2}{*}{$2-10$} & Betaine:lactic acid & BE-LA & $1: 2,1: 5$ & \multirow[t]{2}{*}{$5 \%$ and $10 \%$} & \multirow[t]{2}{*}{12} & \multirow[t]{2}{*}{60} & \multirow[t]{2}{*}{$\begin{array}{l}46.0 \% \text { cellulose content in pretreated } \\
\text { biomass }\end{array}$} & \multirow[t]{2}{*}{$\begin{array}{l}\text { (Kumar, Parikh } \\
\text { et al. 2016) }\end{array}$} \\
\hline & & choline chloride:lactic acid & ChCl-LA & $1: 5,2: 5,1: 9$ & & & & & \\
\hline \multirow[t]{7}{*}{ corn stover } & \multirow[t]{7}{*}{0.38} & choline chloride:glycerol & ChCl-G & $1: 2$ & \multirow[t]{7}{*}{$5 \%$} & \multirow[t]{7}{*}{2} & \multirow[t]{7}{*}{130} & \multirow[t]{7}{*}{ Nearly theoretical glucose yield } & \multirow{7}{*}{$\begin{array}{l}\text { (Xu, Ding et al. } \\
2016)\end{array}$} \\
\hline & & choline chloride:malonic acid & ChCl-MAL & $1: 1$ & & & & & \\
\hline & & choline chloride formic acid & ChCl-FA & $1: 2$ & & & & & \\
\hline & & choline chloride:oxalic acid & $\mathrm{ChCl}-\mathrm{OA}$ & $1: 1$ & & & & & \\
\hline & & choline chloride:acetic acid & ChCl-AA & $1: 2$ & & & & & \\
\hline & & choline chloride:urea & $\mathrm{ChCl}-\mathrm{U}$ & $1: 2$ & & & & & \\
\hline & & choline chloride:citric acid & $\mathrm{ChCl}-\mathrm{CA}$ & $1: 1$ & & & & & \\
\hline \multirow[t]{3}{*}{ Corncob } & \multirow[t]{3}{*}{$0.6-0.76$} & choline chloride:glycerol & $\mathrm{ChCl}-\mathrm{G}$ & $1: 2$ & \multirow[t]{3}{*}{$16: 1$} & \multirow[t]{3}{*}{15} & \multirow[t]{3}{*}{$80,115,150$} & \multirow{3}{*}{$\begin{array}{l}94.8 \% \text { and } 84.8 \% \text { glucose and xylose } \\
\text { yields respectively }\end{array}$} & \multirow{3}{*}{$\begin{array}{l}\text { (Procentese, } \\
\text { Johnson et al. } \\
\text { 2015) }\end{array}$} \\
\hline & & choline chloride:urea & $\mathrm{ChCl-U}$ & $1: 2$ & & & & & \\
\hline & & choline chloride:Imidazole & ChCl-I & $3: 7$ & & & & & \\
\hline \multirow[t]{9}{*}{ Rice straw } & \multirow[t]{9}{*}{$2-10$} & choline chloride:malonic acid & ChCl-MAL & $1: 1$ & \multirow[t]{9}{*}{$5 \%, 10 \%$} & \multirow[t]{9}{*}{$0.5-12$} & \multirow[t]{9}{*}{$60-120$} & \multirow[t]{9}{*}{$87.1 \%$ saccharification efficiency } & \multirow{9}{*}{$\begin{array}{l}\text { (Kumar, Parikh } \\
\text { et al. 2016) }\end{array}$} \\
\hline & & choline chloride:citric acid & ChCl-CA & $1: 1$ & & & & & \\
\hline & & choline chloride:tartaric acid & ChCl-TA & $1: 1$ & & & & & \\
\hline & & choline chloride:lactic acid & ChCl-LA & $1: 1$ & & & & & \\
\hline & & choline chloride:oxalic acid & $\mathrm{ChCl}-\mathrm{OA}$ & $1: 5,1: 9$ & & & & & \\
\hline & & choline chloride:malic acid & ChCl-MA & $1: 1$ & & & & & \\
\hline & & choline chloride:glycerol & $\mathrm{ChCl}-\mathrm{G}$ & $1: 1,1: 2$ & & & & & \\
\hline & & choline chloride:urea & $\mathrm{ChCl}-\mathrm{U}$ & $1: 1$ & & & & & \\
\hline & & choline chloride:1,2-propanediol & ChCl-PD & $1: 1$ & & & & & \\
\hline \multirow[t]{9}{*}{ corncob } & $0.85-0.18$ & choline chloride:lactic acid & ChCl-LA & $1: 2,1: 5,1: 10,1: 15$ & $5 \%$ & $1.5-36$ & $70-110$ & $96.4 \%$ glucose yield & (Zhang, Xia et \\
\hline & & choline chloride:glycolic acid & $\mathrm{ChCl}-\mathrm{GA}$ & $1: 2$ & & & & & al. 2016) \\
\hline & & choline chloride:Levulinic acid & ChCl-LeA & $1: 2$ & & & & & \\
\hline & & choline chloride:malonic acid & ChCl-MAL & $1: 1$ & & & & & \\
\hline & & choline chloride:glutaric acid & ChCl-GlA & $1: 1$ & & & & & \\
\hline & & choline chloride:oxalic acid & $\mathrm{ChCl-OA}$ & $1: 1$ & & & & & \\
\hline & & choline chloride:malic acid & ChCl-MA & $1: 1$ & & & & & \\
\hline & & choline chloride:ethylene glycol & ChCl-EG & $2: 1$ & & & & & \\
\hline & & choline chloride:glycerol & ChCl-G & $2: 1$ & & & & & \\
\hline
\end{tabular}




\subsection{Enzymatic hydrolysis and detoxification of enzymatic hydrolysate}

After the pretreatment process, the structure of pretreated biomass is changed by removing undesirable components (e.g., lignin, hemicellulose), reducing cellulose crystallinity, and increasing the porosity of biomass. Hydrolysis, following pretreatment process, aims to hydrolyze the obtained cellulose into fermentable sugars, which can be further converted into useful products by microorganisms. The enzymatic hydrolysis process usually uses a mixture of cellulase enzymes. The three major cellulase are endoglucanase, exoglucanase, and $\beta$-glucosidase. In addition to cellulases, there are called supplemental enzymes which hydrolyze hemicellulose such as glucuronidase, acetylesterase, xylanase, b-xylosidase, galactomannanase and glucomannanase (Sun and Cheng 2002).

Hydrolysate may not be directly used for fermentation due to the presence of inhibitory compounds in the hydrolysate. The inhibitory compounds affect microbial growth and metabolism (Chandel, Singh et al. 2011). Thus, detoxification is required to reduce the toxicity of those components. Several detoxification methods, including physical, chemical, and biological methods, have been conducted to remove toxic compounds in hydrolysate (Mussatto and Roberto 2004). Typical chemical detoxification methods are calcium hydroxide overliming, activated charcoal treatment, ion exchange resins, and extraction with ethyl acetate (Chandel, Singh et al. 2011). Overliming has been deemed to be one of the most effective and economical methods. Even though the mechanism of this pretreatment is not clearly explained (Van Zyl, Prior et al. 1988), or convert them into other components with less toxicity (Persson, Andersson et al. 2002). The overliming method involves increasing the $\mathrm{pH}$ of hydrolysate to between 9 and 12 by using alkaline such as calcium hydroxide, sodium hydroxide, or ammonium hydroxide (Jönsson, Alriksson et al. 2013). However, this method may cause a loss in sugar concentration depending on the type of biomass hydrolysate, and operation conditions (time, temperature, and $\mathrm{pH}$ ). It was reported that the more the severe operating conditions are, the more sugar 
loss occurs. Up to $68 \%$ glucose loss was reported by Millati et al. when the overliming detoxification of spruce hydrolysate was conducted at $\mathrm{pH} 12$ and $60^{\circ} \mathrm{C}$ for $170 \mathrm{~h}$ using calcium hydroxide (Millati, Niklasson et al. 2002). The inhibitory compounds, such as furan aldehydes and phenols, can be significantly reduced or completely removed via overliming (Millati, Niklasson et al. 2002, Nevoigt 2008). Overliming is used to detoxify pretreated biomass before hydrolysis. Cantarella et, al reported that overlimed detoxified biomass gave higher ethanol production rate than undetoxified biomass (Cantarella, Cantarella et al. 2004)

\subsection{Fermentation}

\subsubsection{SHF and SSF}

The fermentation process converts sugars into more valuable products such as ethanol, butanol, acetoin, and many other products. There are two kinds of fermentation processes widely adopted for lignocellulose conversion: simultaneous scarification and fermentation (SSF) and separate hydrolysis and fermentation (SHF). SSF involves both enzymatic hydrolysis and fermentation of released sugars into a desired final product in one stage. SSF provides many advantages, including (1) requiring low enzymes, (2) saving operating costs, (3) reducing the contamination problem, (4) shortening the process period, and (5) increasing the rate of hydrolysis by converting the released sugars simultaneously (Sun and Cheng 2002). SHF involves the hydrolysis of pretreated biomass followed by a separate fermentation process. This method can be carried out by completing each step under its optimum condition, hydrolysis typically at $50^{\circ} \mathrm{C}$ and fermentation typically at $30^{\circ} \mathrm{C}$ or $39^{\circ} \mathrm{C}$. The main disadvantage of SHF is the possible inhibition of enzymes by released sugars during hydrolysis (Galbe and Zacchi 2002). 


\subsubsection{Acetoin fermentation}

Acetoin is an important platform chemical with wide industrial application (Zhang, Yang et al. 2011, Sun, Zhang et al. 2012). For example, it can be used in foods, cosmetic products, detergents, cigarettes, fabric softeners, and textile treatments (Xiao and Lu 2014). The U.S. Department of Energy lists acetoin as one of the 30 top value-added biomass-based chemicals (Werpy, Petersen et al. 2004).

Table 2.3 summarize the significant studies on the fermentative production of acetoin. Several strains, such as Bacillus subtilis (Zhang, Yang et al. 2011), Bacillus licheniformis (Liu, Zhang et al. 2011), and Serratia marcescens H32 (Sun, Zhang et al. 2012), have been reported as good acetoin producers. B. licheniformis is classified as one of the 10 top acetoin-producing strains (Xiao and Lu 2014). It can produce acetoin up to $78.79 \mathrm{~g} / \mathrm{L}$ ( $\mathrm{Li}$, Wei et al. 2017). Based on the metabolic pathway (Figure 2.4), acetoin can be produced as a dominant product. Depending on the fermentation media and conditions, acetoin can be further converted to 2,3-butanediol (D-(-)-2,3 butanediol, L-(+)-2,3butanediol, or Meso-2,3-butanediol) which can become the dominant end product. Therefore, it is important to design and optimize the fermentation processes toward the accumulation of target products. 
Table 2.3 Acetoin fermentation by different strains.

\begin{tabular}{|c|c|c|c|}
\hline Strains & $\begin{array}{l}\text { Fermentation } \\
\text { conditions }\end{array}$ & $\begin{array}{l}\text { Acetoin } \\
(\mathrm{g} / \mathrm{L})\end{array}$ & Refrence \\
\hline $\begin{array}{l}\text { B. licheniformis WX- } \\
02 \Delta \text { budC } \Delta \text { acoR }\end{array}$ & $\begin{array}{l}37^{\circ} \mathrm{C}, \mathrm{pH} 6,350 \text { then } \\
250 \text { then } 350 \mathrm{rpm}\end{array}$ & 78.79 & (Li, Wei et al. 2017) \\
\hline S. marcescens H32-nox & $28^{\circ} \mathrm{C}, \mathrm{pH} 6,600 \mathrm{rpm}$ & 75.2 & $\begin{array}{l}\text { (Sun, Zhang et al. } \\
\text { 2012) }\end{array}$ \\
\hline B. pumilus XH195 & $37^{\circ} \mathrm{C}, \mathrm{pH} 7,180 \mathrm{rpm}$ & 63.0 & (Xu, Xiao et al. 2012) \\
\hline S. marcescens $\mathrm{H} 32$ & $\begin{array}{l}28^{\circ} \mathrm{C}, \mathrm{pH} 7 \text { then } 6,700 \\
\text { then } 600 \mathrm{rpm}\end{array}$ & 60.5 & $\begin{array}{l}\text { (Sun, Zhang et al. } \\
\text { 2012) }\end{array}$ \\
\hline L. lactis CML B4 & $30^{\circ} \mathrm{C}, \mathrm{pH} 6.5,750 \mathrm{rpm}$ & 59 & $\begin{array}{l}\text { (Roncal, Caballero et } \\
\text { al. 2017) }\end{array}$ \\
\hline B. subtilis TH-49 & $37^{\circ} \mathrm{C}, \mathrm{pH} 7,450 \mathrm{rpm}$ & 56.9 & (Xu, Jia et al. 2011) \\
\hline B. licheniformis 10-1-A & $50^{\circ} \mathrm{C}, \mathrm{pH} 7,400 \mathrm{rpm}$ & 45.1 & (Li, Zhang et al. 2013) \\
\hline $\begin{array}{l}\text { B. licheniformis } \\
\text { MEL09 }\end{array}$ & $37^{\circ} \mathrm{C}, \mathrm{pH} 7.2$ & 41.26 & (Liu, Zhang et al. 2011) \\
\hline $\begin{array}{l}\text { B. licheniformis } \\
\text { DSM } 8785\end{array}$ & $30^{\circ} \mathrm{C}, \mathrm{pH} 6.6,100 \mathrm{rpm}$ & 21.49 & $\begin{array}{l}\text { (Jurchescu, Hamann et } \\
\text { al. 2013) }\end{array}$ \\
\hline $\begin{array}{l}\text { B. licheniformis } \\
\text { WX-02 }\end{array}$ & $45^{\circ} \mathrm{C}, \mathrm{pH} 7$ & $\leq 30$ & (Qi, Kang et al. 2014) \\
\hline
\end{tabular}




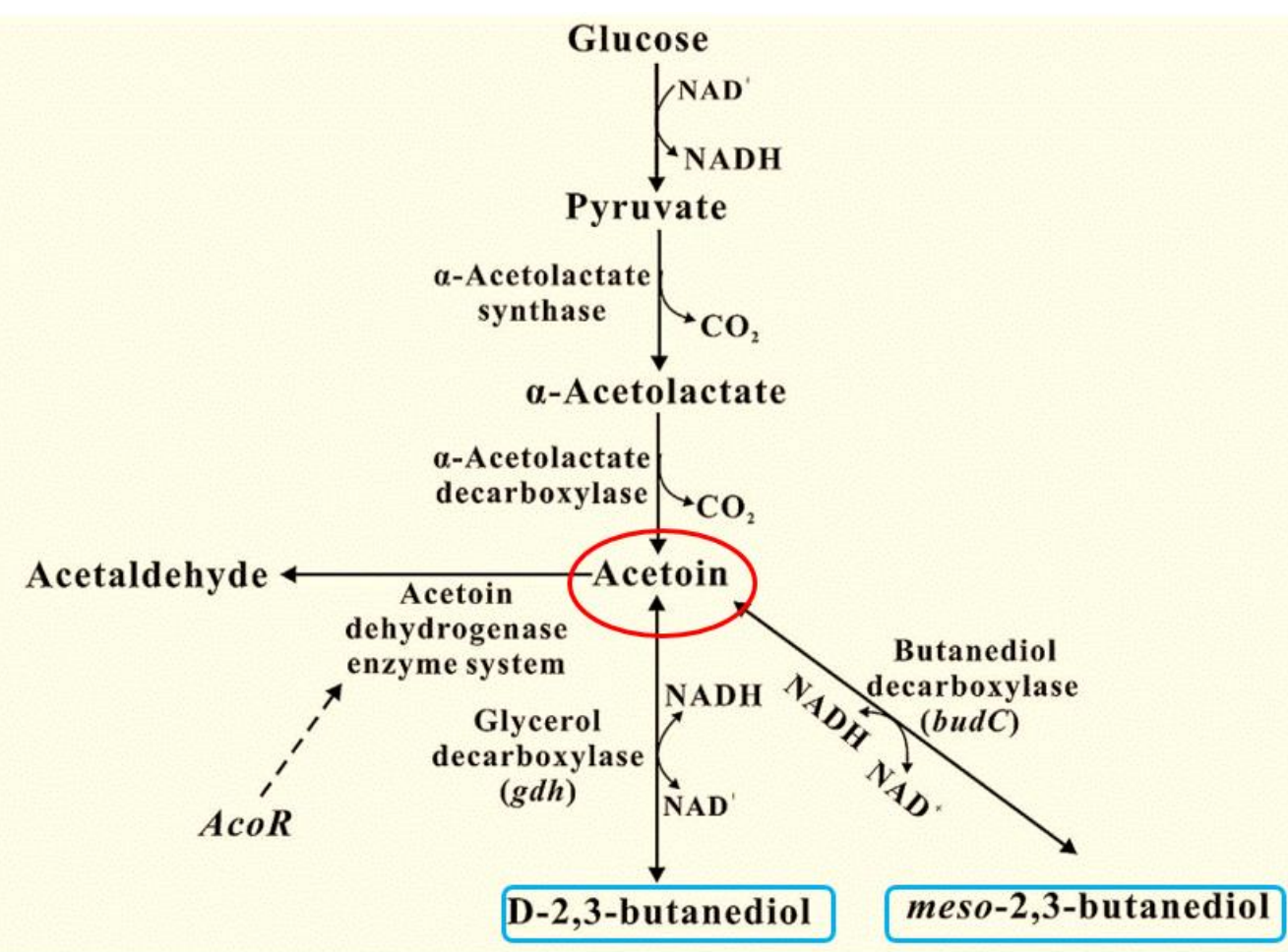

Figure 2.4 Metabolic pathway of acetoin production by $B$. licheniformis WX-02 ( the diagram is from $\mathrm{Li}$ et al. (Li, Wei et al. 2017) 


\section{Chapter 3}

\section{Materials and Methods}

\subsection{Chemicals and raw materials}

Switchgrass was harvested from the Bradford Farm at the University of Missouri in Columbia, Missouri, USA. It was air-dried and ground through a $2 \mathrm{~mm}$ screen by using Wiley Laboratory Mill, Model 4. Hydrolytic enzymes $\left(\mathrm{Cellic}^{\circledR} \mathrm{CTec} 2\right.$ and Cellic $\left.{ }^{\circledR} \mathrm{HTec} 2\right)$ were obtained from Novozymes. $B$. licheniformis (NRRL B-642) was were kindly provided by Agricultural Research Service of the United State Department of Agriculture (Peoria, IL). All the chemicals were analytical grade and purchased from Fisher Scientific.

\subsection{Deep eutectic solvent preparation}

DESs were synthesized by mixing $\mathrm{ChCl}$ with different chemicals as the hydrogen bond donors. Specifically, the mixture was heated at below $90^{\circ} \mathrm{C}$ and stirred $300 \mathrm{rpm}$ for 2 hours or untill a clear homogenous liquid solution formed. The synthesized DESs were stored in a desiccator at room temperature for further use. The chemical composition and mixing ratios of individual chemicals of synthesized DESs are listed in Table 3.1. The HBDs were classified into four groups: polyalcohol (glycerol and ethylene glycol), amide (urea), diazole (imidazole), and carboxylic acids (formic acid, acetic acid, propionic acid, adipic acid, malonic acid, tartaric acid, and oxalic acid)). 
Table 3.1 Synthesis of DESs and chemical structures of HBD.

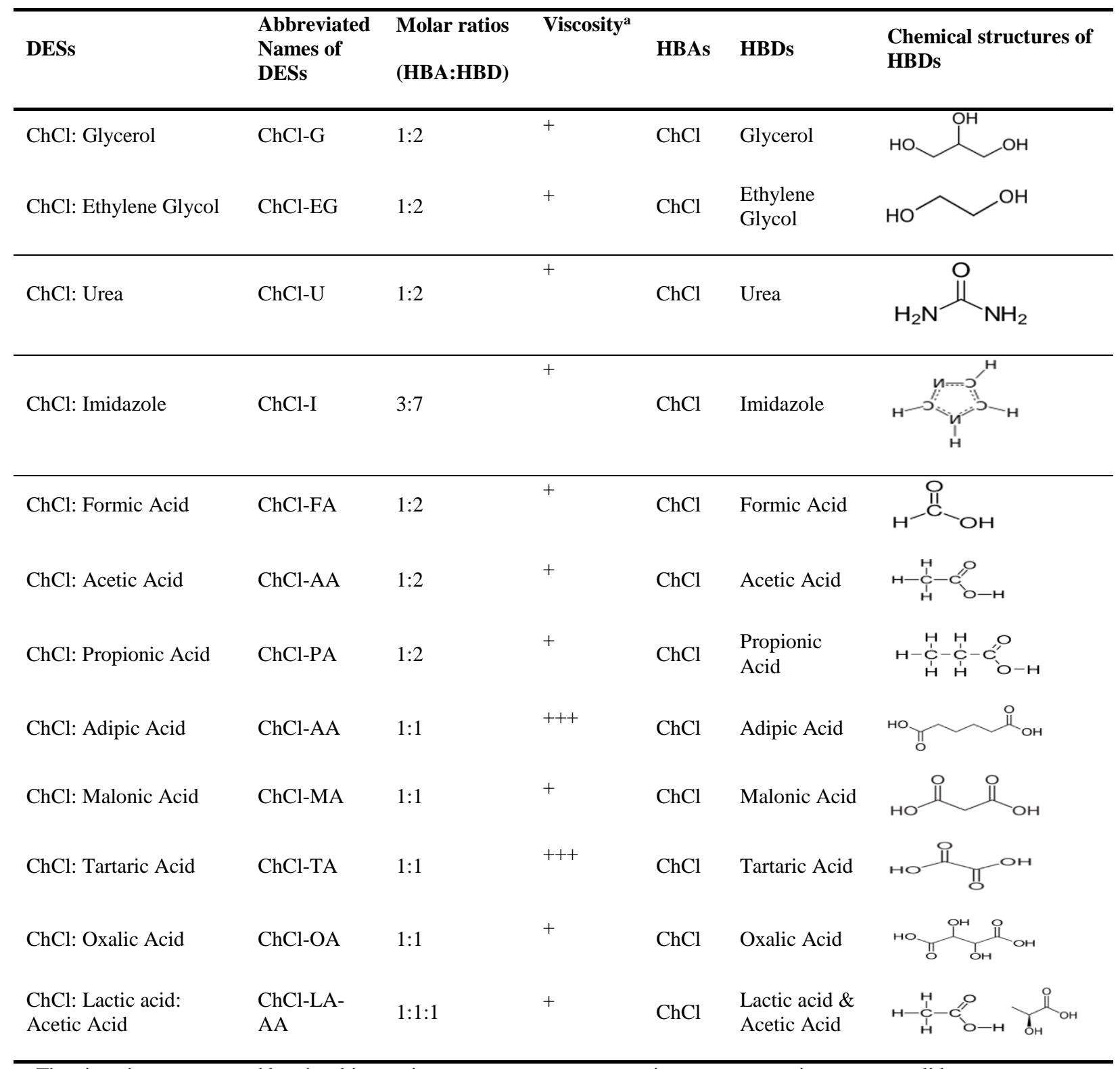

${ }^{\mathrm{a}}$ The viscosity was reported by visual inspection at room temperature: + viscous, ++ very viscous, +++ solid.

\subsection{DES pretreatment of lignocellulosic biomass}

Switchgrass was pretreated with DESs at $130^{\circ} \mathrm{C}$ for 3 hours with $10 \mathrm{wt} \%$ solid loading. In a pressure tube, $2 \mathrm{~g}$ raw switchgrass and $18 \mathrm{~g}$ DES solution were mixed together. The mixture was heated in an oil bath to the target temperature and stirred every 20 min manually by using a stirring rod. The reaction time was counted when the mixture reached the target temperature. The heating-up time for 
small scale was 20 to $30 \mathrm{~min}$, while for big scale was around $45 \mathrm{~min}$. After DES pretreatment, the pretreatment slurry was added with $30 \mathrm{~g}$ of hot DI water $\left(80^{\circ} \mathrm{C}\right)$ and then filtered through1.6- $\mu \mathrm{m}$ glass fiber filter paper by vacuum filtration. The solid residue was washed with $80^{\circ} \mathrm{C}$ DI water several times until neutral $\mathrm{pH}$ was reached, collected, and then stored in sealed plastic bags at $-20^{\circ} \mathrm{C}$ prior to use. The experiments were conducted in duplicate. The schematic diagram of DES pretreatment is shown in Figure 3.1.

In order to prepare enough samples for high solid enzymatic hydrolysis, ChCl-LA-AA pretreatment was scaled up ten folds by mixing $20 \mathrm{~g}$ raw switchgrass with $180 \mathrm{~g}$ ChCl-LA-AA. The reaction mixture was pretreated for $3 \mathrm{~h}$ (excluding heating-up time) at $130^{\circ} \mathrm{C}$ with continuous stirring at $300 \mathrm{rpm}$ using a magetic stirrer bar to avoid mass and heat transfer limitations. The pretreated solid was collected as described above and stored at $-20^{\circ} \mathrm{C}$ for further use.

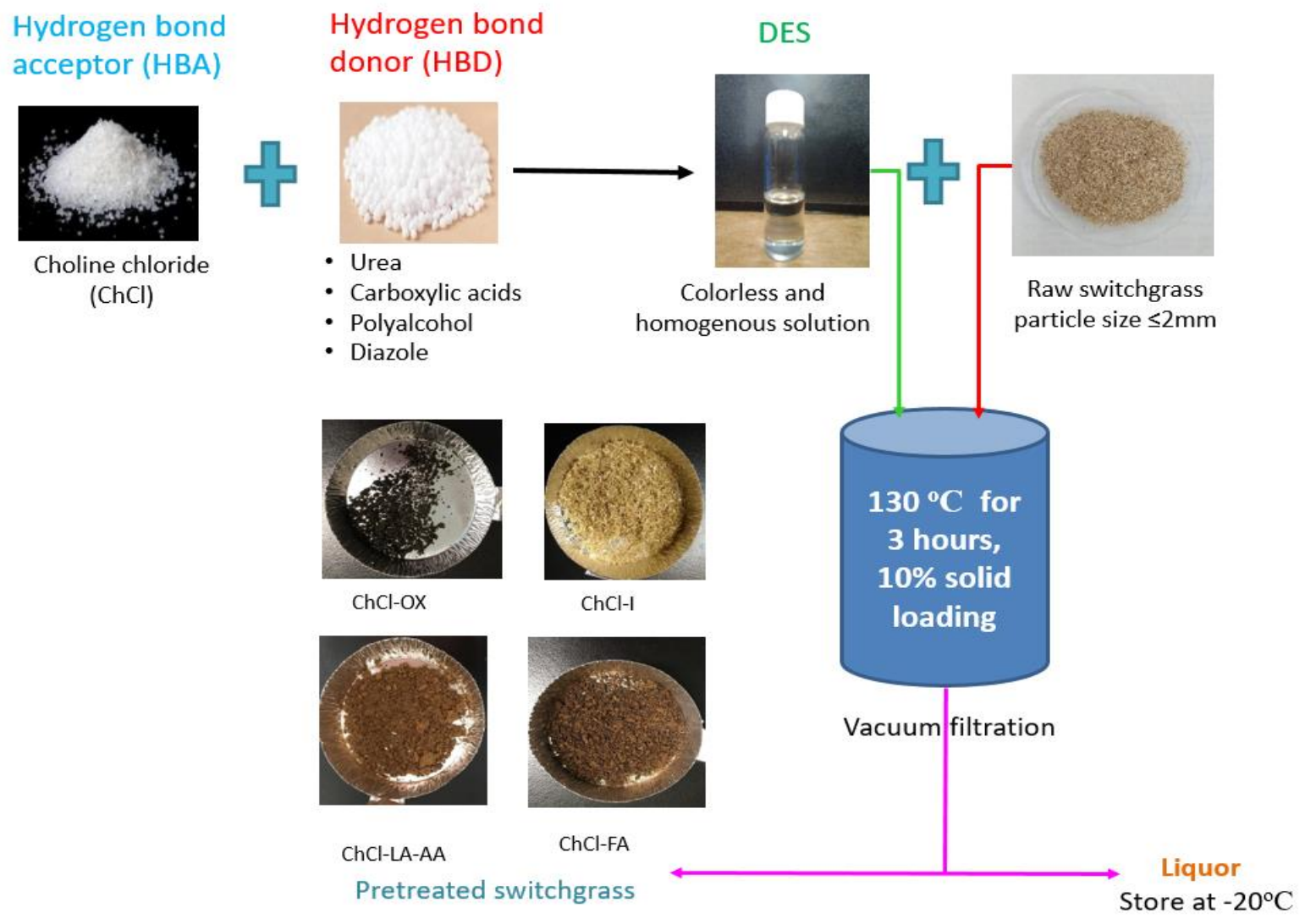

Figure 3.1 DES synthesis and DES pretreatment. 


\subsection{Enzymatic hydrolysis}

NREL protocol was followed to evalutate the cellulose digestibility (Dowe and McMillan, 2001). In brief, enzymatic hydrolysis of the pretreated and raw switchgrass was carried out in a $50 \mathrm{~mL}$ Erlenmeyer flask. The pretreated biomass is added to sodium citrate buffer $(50 \mathrm{mM}, \mathrm{pH} 4.8)$ with a solid loading of $2 \%(\mathrm{w} / \mathrm{w})$ to reach a working volume of $20 \mathrm{~mL}$. The Cellulase (CTec 2) and hemicellulase (HTec 2) were loaded at 20 and $2 \mathrm{mg}$ protein/g solid, respectively. Sodium azide $(0.002$ w/v \%) was added to prevent microbal contamination during the hydrolysis process. The mixture was then hydrolyzed at $50^{\circ} \mathrm{C}$ with $150 \mathrm{rpm}$ for $48 \mathrm{~h}$. After the hydrolysis was done, the samples were boiled for 10 minutes to deactivate enzyme and then stored at $-20^{\circ} \mathrm{C}$ for later analysis. The experiments were conducted in duplicate.

High solid enzymatic hydrolysis was conducted to investigate the effects of solid loading on the sugar release and also prepare concentrated sugar solution for fermentation. The tests were conducted in a $250 \mathrm{~mL}$ Erlenmeyer flask with $50 \mathrm{~mL}$ working volume. The ChCl-LA-AA pretreated switchgrass was added to sodium citrate buffer $(50 \mathrm{mM}, \mathrm{pH} 4.8)$ with two feeding strategies (batch and feed batch). For batch feeding, three solid loadings, namely 5\%, 10\%, and 20\% were studied. Cellulase (CTec 2) and hemicellulase (HTec 2) were loaded in the beginning at 20 and $2 \mathrm{mg}$ protein/g solid, respectively. For fed batch enzymatic hydrolysis, 5\% solid loading and corresponding enzyme loading were added every $12 \mathrm{~h}$ for the first $48 \mathrm{~h}$ to reach a total solid loading of $20 \%$. The hydrolysis was conducted in duplicate at $50^{\circ} \mathrm{C}$ at $150 \mathrm{rpm}$ for $96 \mathrm{~h}$ under non-sterile condition. The hydrolyis was terminated as described above and the hydrolysate samples were collected and stored at $-20^{\circ} \mathrm{C}$ for further use. The sugar yields for low solid and high enzymatic hydrolysis were calculated using the following equations: 
For low solid loading:

$$
\begin{gathered}
\text { Glucose yield }(\%)=\frac{(G l u+1.053 \mathrm{Cel}) \times m_{r}}{1.111 \times F_{C} \times D M} \times 100 \% \\
\text { Xylose yield }(\%)=\frac{X y l \times m_{r}}{1.136 \times F_{X} \times D M} \times 100 \%
\end{gathered}
$$

For high solid loading:

$$
\begin{gathered}
\text { Glucose yield }^{*}(\%)=\frac{\frac{m_{r}-m_{\text {ins }}}{S G} \times(G l u+1.053 \mathrm{Cel}) \times V_{h}}{1.111 \times F_{C} \times D M} \times 100 \% \\
\text { Xylose yield }(\%)=\frac{\frac{m_{r}-m_{\text {ins }}}{S G} \times X y l \times m_{r}}{1.136 \times F_{X} \times D M} \times 100 \%
\end{gathered}
$$

Where $\mathrm{m}_{\mathrm{r}}$ is mass of total reaction $(\mathrm{g}), \mathrm{m}_{\mathrm{ins}}$ is mass of insoluble solid left after enzymatic hydolysis $(\mathrm{g}), \mathrm{SG}$ is the specific gravity of liquid phase $(\mathrm{g} / \mathrm{L})$, Glu is the released glucose concentration $(\mathrm{g} / \mathrm{L})$, $\mathrm{Cel}$ is the released cellobiose concentration $(\mathrm{g} / \mathrm{L}), \mathrm{Xyl}$ is the released xylose concentration $(\mathrm{g} / \mathrm{L}), \mathrm{F}_{\mathrm{C}}$ is the fraction of celluose in the raw or pretreated biomass, $F_{X}$ is the fraction of hemicellulose in the raw or pretreated biomass, DM is the dry mass of the raw or pretreated biomass, and $\mathrm{V}_{\mathrm{h}}$ is the volume of collected hydrolysate. ${ }^{*}$ The equation is adapted from Kristensen (Kristensen, Felby et al. 2009)

\subsection{Detoxification of Switchgrass Hydrolysate}

Since the obtained hydrolysate of pretreated biomass had high toxicity to B. licheniformis, the overliming detoxification method was used to remove the toxic compounds in the hydyrolysate. Calcium hydroxide $\mathrm{Ca}(\mathrm{OH})_{2}$ was added to the hydrolysate to bring the $\mathrm{pH}$ to 10 , and the slurry was then treated at $30^{\circ} \mathrm{C}$ with an agitation rate of $200 \mathrm{rpm}$ for $1 \mathrm{~h}$. The liquor was collected by centrifugation and stored at $-20^{\circ} \mathrm{C}$ prior to use. 


\subsection{Seed culture preparation}

B. licheniformis (NRRL B-642) was maintained at $4^{\circ} \mathrm{C}$ in a Luria-Bertani (LB) agar comprised

of $(\mathrm{g} / \mathrm{L})$ : trypeptone 10 , yeast extreact 5 , sodium chloride 10 , and agar 15 . One loop of B. licheniformis was inoculated into seed medium which was composed of the following components $(\mathrm{g} / \mathrm{L})$ : trypeptone 10 , yeast extract 5 , sodium chloride 10 , and glucose 20 . The $\mathrm{pH}$ of the seed medium was adjusted to 6.0 by using $5 \mathrm{M} \mathrm{NaOH}$ and $2 \mathrm{M} \mathrm{H}_{2} \mathrm{SO}_{4}$. After $16-18 \mathrm{~h}$, the seed culture was harvested by centrifuging at $6000 \times \mathrm{g}$ for $5 \mathrm{~min}$ and washed twice with $0.9 \mathrm{wt} \%$ sodium chloride solution. After washing, the cells were diluted by DI water and inoculated into fermentation media to abtain an initial optical density $\left(\mathrm{OD}_{600}\right)$ of approximately 0.5 . The fermentation media and fermentation tests were described in the subsections below.

\subsection{Acetoin fermentation}

To investigate the effects of initial $\mathrm{pH}$ and temperature on acetoin fermenation, four levels of $\mathrm{pH}(5,5.5,6$, and 6.5$)$ and two levels of temperatures $\left(30^{\circ} \mathrm{C}\right.$ and $\left.45^{\circ} \mathrm{C}\right)$ were tested. Based on onefactor-one-time design, the temperature of $30^{\circ} \mathrm{C}$ was used for $\mathrm{pH}$ tests while an initial $\mathrm{pH}$ of 6 was used for temperature tests. For all the above fermentation tests, the fermentation media was LB broth supplemented with $50 \mathrm{~g} / \mathrm{L}$ glucose and the initial $\mathrm{pH}$ of the medium was adjusted by using $5 \mathrm{M} \mathrm{NaOH}$ or $2 \mathrm{M} \mathrm{H}_{2} \mathrm{SO}_{4}$. The aerobic fermentation was conducted in a $250 \mathrm{~mL}$ Erlenmeyer flask with working volume of $50 \mathrm{~mL}$ and $200 \mathrm{rpm}$ for $48 \mathrm{~h}$.

For separate hydrolysis and fermentation (SHF), an aerobic fermentation was carried out in a $250 \mathrm{~mL}$ Erlenmeyer flask with $25 \mathrm{~mL}$ working volume. The undetoxified or detoxifed hydrolysate resulting from 20\% solid loading enzymatic hydrolysis of ChCl-LA-AA -pretreated switchgrass was added to LB broth to obtain approximately $50 \mathrm{~g} / \mathrm{L}$ equavilant initial glucose concentration. The initial $\mathrm{pH}$ of the fermentation media was adjusted to 6 . The fermentation media were autoclaved at $121^{\circ} \mathrm{C}$ for 
$15 \mathrm{~min}$. The fermentation was conducted at $30^{\circ} \mathrm{C}$ with $200 \mathrm{rpm}$ for $48 \mathrm{~h}$. The fermentation broth was collected at the end of fermentation for further analysis.

Simultaneous saccharification and fermentation (SSF) was carried out in a $250 \mathrm{~mL}$ Erlenmeyer flask with $25 \mathrm{~mL}$ working volume. The above prepared ChCl-LA-AA -pretreated switchgrass was loaded at $10 \mathrm{wt} \%$ to the flask containing LB broth and citrate buffer. The intial $\mathrm{pH}$ was adjusted to be 6.0. After autoclave, Cellulase (CTec 2) and Hemicellulase (HTec 2) were loaded at 20 and $2 \mathrm{mg}$ protein/g solid, respectively. The fermentation media were autoclaved at $121^{\circ} \mathrm{C}$ for $15 \mathrm{~min}$. The SSF condition was conducted at $30^{\circ} \mathrm{C}$ at $200 \mathrm{rpm}$ for $48 \mathrm{~h}$. The fermentation broth was collected at the end of fermenation for further analysis.

\subsection{Analytical methods}

The structural carbohydrates and lignin of both the pretreated and raw switchgrass were analyzed following two-stage acid hydrolysis as decribed in the NREL protocol (Sluiter, Hames et al. 2008). In brief, the samples were hydrolyzed first with $72 \%$ sulfuric acid at $30^{\circ} \mathrm{C}$ for $60 \mathrm{~min}$ followed by diluted acid hydrolysis ( $4 \%$ sulfuric acid) at $121^{\circ} \mathrm{C}$ for $60 \mathrm{~min}$. The hydrolysate was filtered to obtain the solid fraction and liquor. The acid insoluble lignin was determined by using a gravimetric method, while the acid soluble lignin was determined by UV-Vis spectrophotometry (GENESYS 10S UV-VIS spectrophotometer) at a wavelength of $320 \mathrm{~nm}$. The liquor (filtrate) was neutralized and analyzed for

simple sugars using HPLC system (Agilent 1100 series) equipped with a quaternary pump, autosampler, and refractive index detector (RID). A Bio-Rad Aminex HPX-87P column $(300 \times 7.8 \mathrm{~mm}$ ) was used for sugar analysis. The column temperature was maintained at $80^{\circ} \mathrm{C}$ and the mobile phase was, HPLC grade water, eluting at $0.6 \mathrm{~mL} / \mathrm{min}$.

$$
\text { Glucan content }(\%)=\frac{G l u_{f} \times V_{f}}{0.9 \times 0 \mathrm{DM}} \times 100 \%
$$




$$
X y \text { lan content }(\%)=\frac{X y l_{f} \times V_{f}}{0.88 \times \mathrm{ODM}} \times 100 \%
$$

$$
\text { Lignin content }(\%)=(\text { acid insoluble lignin }+ \text { acid soluble lignin }) \times 100 \%
$$

lignin removal $(\%)=\left(1-\left(\frac{\text { lignin content } \% \text { in pretreated switchgrass }}{\text { lignin content } \% \text { in raw switchgrass }} \times\right.\right.$ solid recovery $\left.)\right) \times 100$

Hemicelulose removal $(\%)=\left(1-\left(\frac{\text { xylan content } \% \text { in pretreated switchgrass }}{\text { xylan content } \% \text { in raw switchgrass }} \times\right.\right.$ solid recovery $\left.)\right) \times 100$

$$
\text { Cellulose removal }(\%)=\left(1-\left(\frac{\text { glucan content } \% \text { in pretreated switchgrass }}{\text { glucan content } \% \text { in raw switchgrass }} \times \text { solid recovery }\right)\right) \times 100
$$

Where $G l u_{f}$ is concentration of glucose in filtrate, $X y l_{f}$ is concentration of xylose in filterate, $V_{f}$ is volume of the filtrate, and ODM is the oven dry mass.

Acetoin and glucose concetration in the fermentation broth were determined using the above discriped HPLC system. The column was Aminex HPX-87H column $(300 \times 7.8 \mathrm{~mm})$. The mobile phase was $5 \mathrm{mM} \mathrm{H} \mathrm{SO}_{4}$ with flow rate of $0.6 \mathrm{~mL} / \mathrm{min}$ at $65^{\circ} \mathrm{C}$. All the samples were filtered through a 0.45 $\mu \mathrm{m}$ nylon membrane before injection. The acetoin yield was calculated as follows:

$$
\text { Acetoin yield }(\%)=\frac{\mathrm{g} \text { mass acetoin produced }}{\mathrm{g} \text { sugar consumed }} \times 100 \% \text {. }
$$




\section{Chapter 4}

\section{Results \& Discussion}

\subsection{DES pretreatment}

\subsubsection{Composition of raw and pretreated switchgrass}

After DES pretreatment, the chemical composition of switchgrass was changed depending on the type of DESs used. The contents of major cell wall components were $33.4 \%, 18.7 \%$, and $20.4 \%$ for glucan, xylan, and lignin, respectively. The ChCl-polyalcohol combination did not show obvious effects in switchgrass pretreatment, indicating that this group of DESs was not or slightly effective for the pretreatment (Table 4.1). ChCl-G pretreated switchgrass showed a similar composition to that of raw switchgrass. ChCl-EG pretreated switchgrass had a higher glucan content than raw switchgrass while their xylan contents or lignin contents were close to each other.

For the ChCl-amide group, particularly $\mathrm{ChCl}-\mathrm{U}$, the glucan and xylan contents of the pretreated switchgrass were $3.2 \%$ and $1.5 \%$ higher than those of raw switchgrass, respectively, while the lignin content was $2.1 \%$ lower. Procentese and coworkers studied the pretreatment of corn cob by ChCl-U and found that this pretreatment increased glucan and xylose contents slightly when corn cob was pretreated at 80 and $115^{\circ} \mathrm{C}$ for $15 \mathrm{~h}$ (Procentese, Johnson et al. 2015). The difference in the pretreatment effectiveness could be due to the differences in feedstock species and pretreatment conditions.

For ChCl-Imidazole, the glucan and xylan contents of the pretreated switchgrass were $39.6 \%$ and $22.1 \%$, respectively, which were correspondingly $6.9 \%$ and $3.4 \%$ over those of raw switchgrass. The lignin content of the pretreated switchgrass was $6.2 \%$ lower than that of raw switchgrass and other pretreated samples. The ability of imidazole-based DES to reduce lignin content was reported for the pretreatment of corn cob (Procentese, Johnson et al. 2015). The significant effectiveness of imidazolebased DES was most likely due to the interaction between imidazole rings and phenyl rings of lignin. 
Similar effects were also observed with imidazolium-based ionic liquid pretreatment. The imidazolium cation of ILs has been shown to play a significant role in delignification (van Osch, Kollau et al. 2017).

Table 4.1 Effects of DES pretreatment on the composition of switchgrass.

\begin{tabular}{lllll}
\hline & DESs & \multicolumn{3}{l}{ Composition content (\%) } \\
\hline \multirow{3}{*}{ ChCl- Polyalcohol } & Raw & Glucan & Xylan & Lignin \\
\cline { 2 - 5 } & ChCl-G & $33.4 \pm 0.24$ & $18.7 \pm 0.31$ & $20.4 \pm 0.06$ \\
& ChCl-EG & $34.3 \pm 1.23$ & $19.7 \pm 0.08$ & $19.2 \pm 2.03$ \\
\hline ChCl- Diazole & ChCl-I & $36.7 \pm 0.68$ & $18.0 \pm 1.54$ & $19.5 \pm 0.01$ \\
\hline ChCl- Amide & ChCl-U & $39.6 \pm 0.23$ & $22.1 \pm 0.24$ & $14.2 \pm 0.15$ \\
\hline ChCl- Carboxylic acid & ChCl-FA & $55.5 \pm 0.61$ & $5.8 \pm 0.06$ & $24.4 \pm 0.41$ \\
& ChCl-AA & $51.2 \pm 0.26$ & $11.8 \pm 0.05$ & $19.2 \pm 2.03$ \\
& ChCl-PA & $48.6 \pm 0.76$ & $12.8 \pm 2.34$ & $18.57 \pm 1.42$ \\
\cline { 2 - 5 } & ChCl-Ad.A & $45.3 \pm 3.52$ & $12.8 \pm 2.08$ & $19.2 \pm 1.11$ \\
& ChCl-MA & $42.0 \pm 1.12$ & $14.2 \pm 1.23$ & $22.1 \pm 0.03$ \\
& ChCl-OA & $43.9 \pm 1.57$ & $11.5 \pm .93$ & $38.8 \pm 0.38$ \\
& ChCl-TA & $41.8 \pm 0.66$ & $7.6 \pm 1.016$ & $28.0 \pm 1.61$ \\
\cline { 2 - 5 } & ChCl-LA-AA & $53.4 \pm 3.2$ & $15.2 \pm 3.8$ & $21.8 \pm 0.3$ \\
\hline
\end{tabular}

The ChCl-Carboxylic acid group showed the best performance in increasing glucan content. $\mathrm{ChCl}-\mathrm{FA}, \mathrm{ChCl}-\mathrm{AA}$, and $\mathrm{ChCl}-\mathrm{PA}$ increased the glucan content of switchgrass drastically. ChCl-FA DES pretreatment appeared to be the most efficient for fractionating switchgrass, leading to the highest cellulose content $(55.5 \%)$ and lowest xylan content $(5.8 \%)$ across all the pretreated solids. However, the lignin content was increased to $24.4 \%$ which was higher than the raw switchgrass. Similar increases in lignin content were observed with Ch-OA and Ch-TA pretreated switchgrass. Such increase could be attributed to redeposition of lignin onto the pretreated solids, forming so-called as pseudo-lignin. Many prior studies especially on acid-based pretreatment showed such phenomena (Nguyen, Tucker et al. 1999). For example, Cristóba et al. reported the similar finding for dilute acid pretreatment of olive tree (Cara, Ruiz et al. 2008) . Xu et al. also reported that Ch-FA pretreatment led to an increase in 
lignin content of corn stover from $24.1 \%$ to $27.1 \%$ (Xu, Ding et al. 2016). Compared to a binary mixture of $\mathrm{ChCl}$ and any of the carboxylic acids (except $\mathrm{Ch}-\mathrm{FA}$ ), the pretreatment using the ternary mixture containing two carboxylic acids AA and LA led to a higher glucan content in the pretreated switchgrass. However, the xylan and lignin contents in such pretreated solid were about $15 \%$ and $22 \%$, respectively, which indicated that Ch-AA-LA stands out as a good candidate for DES pretreatment in terms of decent holocellulose content in the pretreated switchgrass.

\subsubsection{Cell wall component loss}

As a result of DES pretreatment, switchgrass lost some of its cell wall components, such as lignin and hemicellulose. Figure 4.1 shows the solid recovery after pretreatment. Pretreatment that had no or little effectiveness, such as $\mathrm{ChCl}-\mathrm{G}$ and $\mathrm{ChCl}-\mathrm{EG}$, as discussed above, led to high solid recovery. The low solid recovery was obtained as a result of $\mathrm{ChCl}$-carboxylic acid DES pretreatment, largely due to significant xylan loss. Ch-FA and CC-LA-AA pretreatment resulted in similar solid recovery (about 63\%), which were the lowest solid recovery (about 63\%) among all the tested DESs. Solid recovery of other carboxylic acid-based DESs ranged from $65-75 \%$ while those of Ch-I and Ch-U were about $85 \%$.

The loss of solids after pretreatment was attributed to the dissolution and degradation of structural and non-structural components in switchgrass. The removal of structural components, particularly cell wall components, was depicted in Figure 4.2. Ch-I pretreatment led to the highest lignin removal (40.86\%) (Figure 4.2). While all carboxylic acid based DESs were effective for switchgrass pretreatment, the resulting lignin removal was not necessarily high. As briefly mentioned in subsection 4.1.1, pseudo-lignin can be formed as a result of acid-based pretreatment, which accounted for a portion of total lignin content in pretreated biomass. The formation of pseudo-lignin may not be an issue with Ch-AA, Ch-PA, Ch-AdA, and Ch-LA-AA pretreatment, as these DESs 


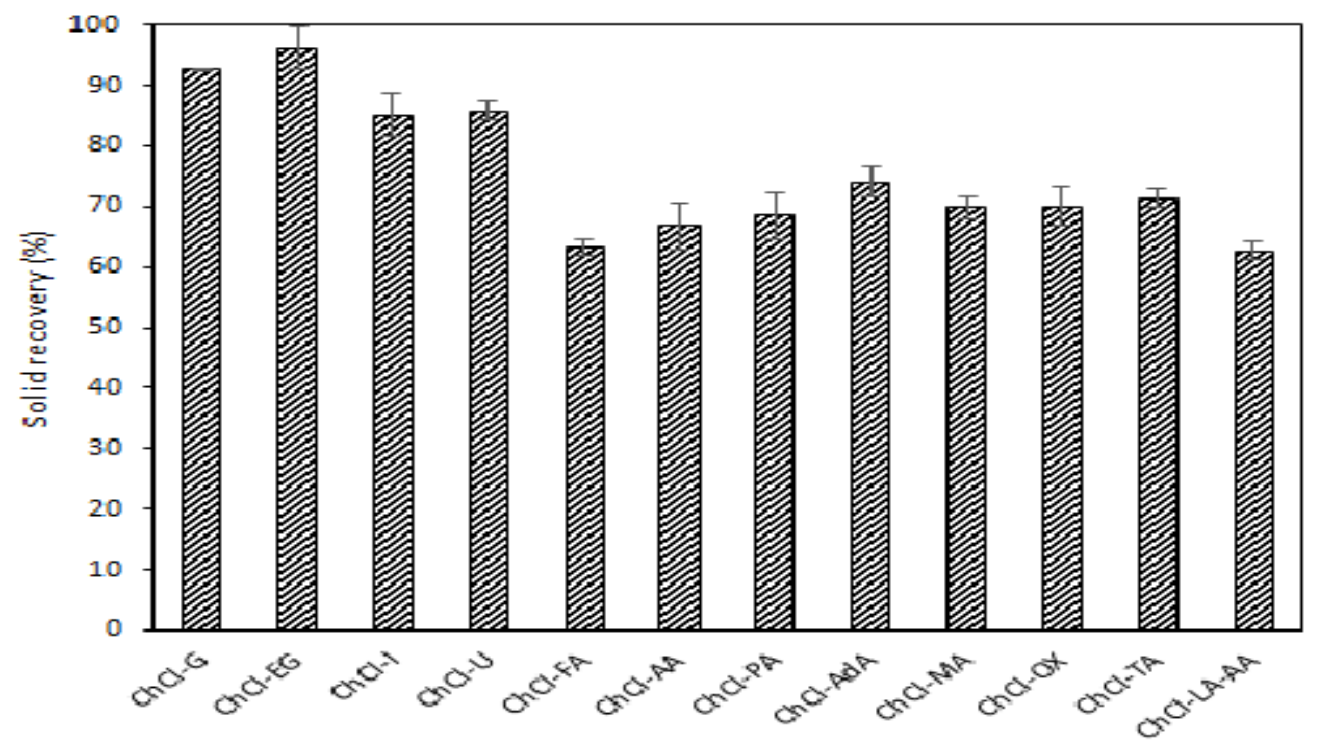

Figure 4.1 Solid recovery after DES pretreatment

removed $30-40 \%$ of the lignin from switchgrass. Nevertheless, across all the carboxylic acid based DES pretreated solids, it was hard to find a correlation between lignin content and cellulose digestibility, as discussed in subsection 4.13. In terms of xylan removal, carboxylic acid based DESs appeared to be most effective. The highest xylan removal $(81 \%)$ was obtained from Ch-FA pretreatment. Ch-TA was also very effective for removing xylan and about $65 \%$ xylan was removed by this DES pretreatment. Theoretically, cellulose can not be degraded by any of the tested DESs in this study. A few prior studies reported cellulose dissolution by DESs, but these studies were mostly based on pure cellulose, and the reproducibity of these studies was poor (van Osch, Kollau et al. 2017). Although further confirmation is needed, we believe that the cellulose removal as reported in Figure 4.2 was primarily due to experimetal error (within $\pm 10 \%$ ) caused by several factors during operation. 


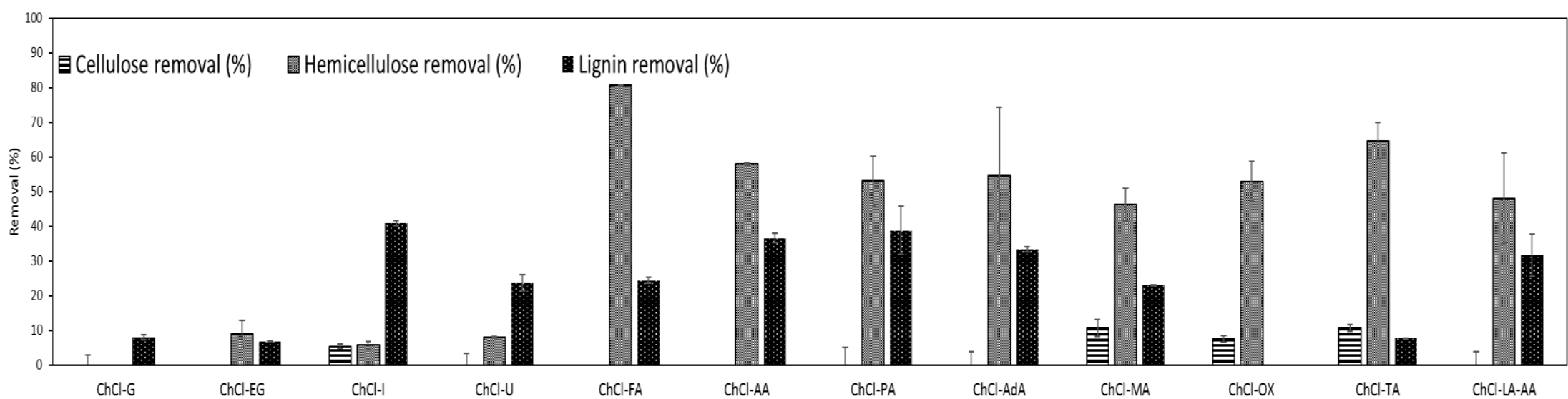

Figure 4.2 Cell wall component loss as a result of DES pretreatment. 


\subsubsection{Cellulose digestibility}

The purpose of DES pretreatment was to enhance switchgrass digestibility and faciliate the release of fermentable sugars for acetoin production. We thus evaluated the effectiveness of DES pretreatment based on cellulose digestibility. As described in Chapter 3 all the enzymatic hydrolysis tests were conducted with a solid loading of $2 \%$ at $50^{\circ} \mathrm{C}$ and $\mathrm{pH}$ of 5.0 for $48 \mathrm{~h}$. The use of a low loading solid was to avoid any potential substrate inhibtion.

The glucose yields of switchgrass pretreated by $\mathrm{ChCl}-\mathrm{G}$ and $\mathrm{ChCl}-\mathrm{EG}$ were $16.7 \%$ and $14.1 \%$, respectively, which were even lower than those of raw switchgrass. As discussed above, $\mathrm{ChCl}-\mathrm{G}$ and $\mathrm{ChCl}-\mathrm{EG}$ were not effective for the pretreatment of switchgrass. It remains unclear what contributed to the reduced sugar yields. One possible explanation is that the condensation of chemical structures of switchgrass when it was subjucted to the pretreatment using $\mathrm{ChCl}-\mathrm{G}$ and ChCl-EG. Compared to the above two polyachohol-based DESs, ChCl-U pretreated switchgrass gave higher sugar yields than raw switchgrass. The above results showed that $\mathrm{ChCl}-\mathrm{U}$ pretreatment enhanced cellulose digestiblity, which was largely attributed to significant lignin removal.

Although $\mathrm{ChCl}$-LA-AA did not increase the glucan content as much as $\mathrm{ChCl}$-FA or reduce the lignin content as much as $\mathrm{ChCl}-\mathrm{I}$, it showed the best preformance in enhancing the cellulose digestiblity of switchgrassas (Figure 4.3a). The second highest glucose yield was $80.38 \%$ due to ChCl-FA pretretment. Glucose yield is not necessarily correlated with glucan content of pretreated biomass (Cara, Ruiz et al. 2008). Lignin removal also does not necessarily indicate enhanced cellulose digestibility (Fu, Mazza et al. 2010). Some other carboxylic acid-based DESs also showed decent glucose yields. For example, about $62 \%$ glucose yields were obtained from the pretreated switchgrass by $\mathrm{ChCl}-\mathrm{AdA}$ and $\mathrm{ChCl}-\mathrm{MA}$ and about $60 \%$ glucose yield resulted from ChCl-AA pretreatment. 
In terms of xylose yields, most of pretreated switchgrass largely followed a similar trend to their glucose yields but with much lower values. Although attractive xylose yields were obtained with some pretreated switchgrass, it may not necessarily indicate that such DESs were prefered for improving xylose digestiblities. Unlike cellulose, signifant amounts of xylan were solublized into pretreatment slurry if the pretreatment was effective enough. For example, Ch-FA pretreated switchgrass had the lowest xylan content but gave very high xylose yield. There was more xylose present in the streams other than in enzymatic hydrolysate. Furthermore, there was no correlation between xylose yields and xylan content of pretreated switchgrass (Table 4.1 and Figure 4.3.b). 
(a)
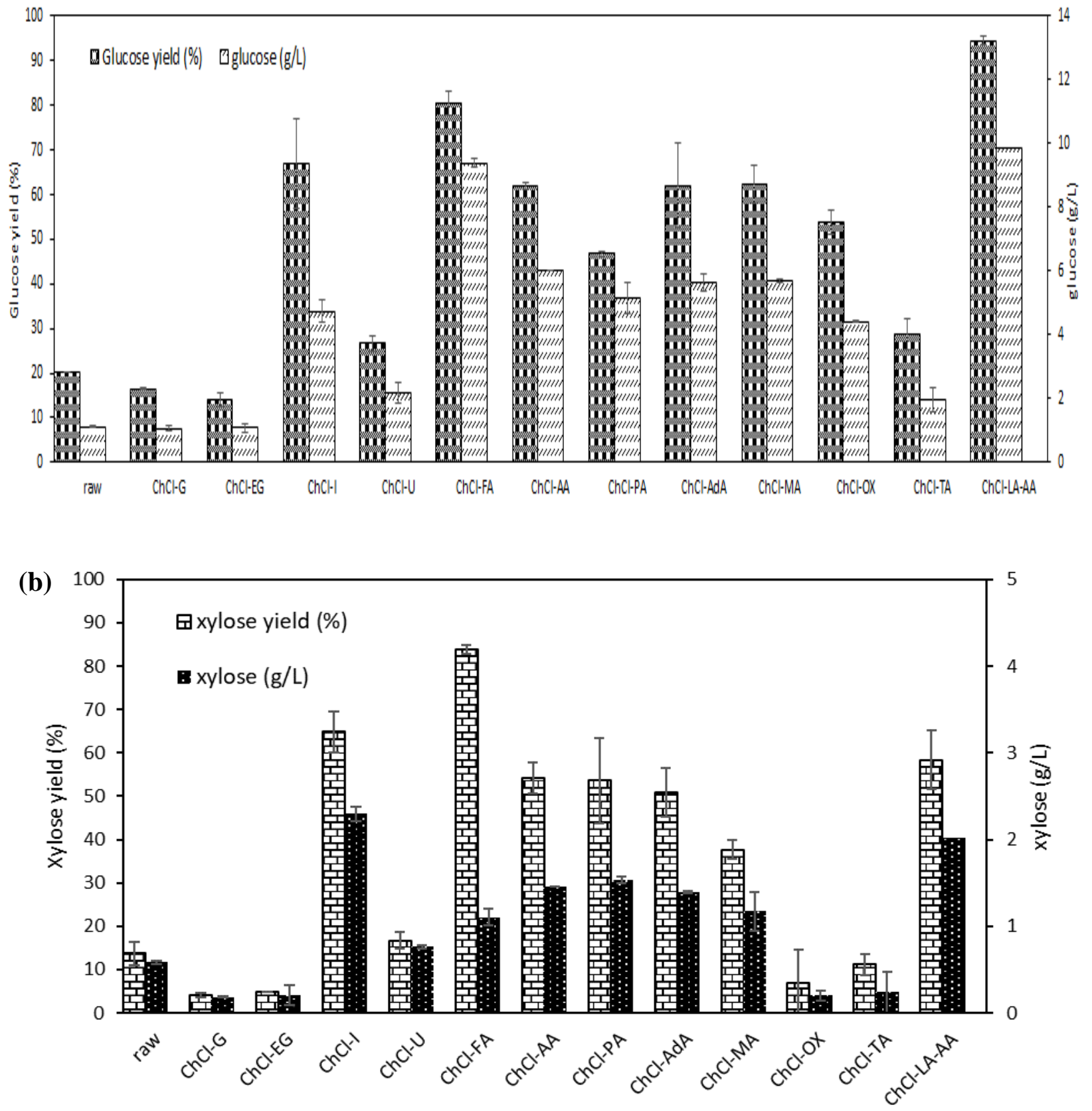

Figure 4.3 Effects of DES pretreatment on switchgrass digestibility (a) glucose yields, (b) xylose yields. 


\subsection{High Solid-Loading Enzymatic Hydrolysis}

As one of the most effective pretreatment, the ternary mixture of DES (Ch-LA-AA) was selected for high solid-loading enzymatic hydrolysis tests as well as prepraring the concentrated biomass hydrolysate for fermenation. The results showed that there was no significant difference in the sugar yields between 20B and 20FB after 96 hours of enzymatic hydrolysis (Table 4.2). Relatively good linear relationship between glucose concentration and solid loading was obtained (Table 4.3). However, the glucose yields calculated based on Equation 3 for high solid enzymatic hydrolysis were $83.67 \%, 86.17 \%$, and $90.35 \%$ for 20B, 10B, and 5B, respectively (Table 4.2). This indicated that $20 \%$ solid loading affected the release of sugars. Free water content and substrate/product inhibition are two main factors influencing sugar release from high solid enzymatic hydrolysis. When water content is increased, the viscosity of slurry decreases, which makes the solublization of solids easier and overcomes possible mass transfer limitation. Furthermore, lowering the viscosity of hydrolysis medium leads to reduced power required for mixing (Modenbach and Nokes 2012). As the hydrolytic enzymes were overloaded in our study, substrate inihibtion shoud not be an issue, or be very minor (if any). In terms of production inhibition, more cellobiose was accumulated along with increased levels of glucose. This is due to feedback inhibition of $\beta$-glucosidase that is responsble for hydrolyzing cellobiose to glucose. High glucose level generally leads to the reduced acitivity of $\beta$-glucosidase (Sun and Cheng 2002, Chen and Liu 2016). 
Table 4.2 Sugar production via high solid-loading enzymatic hydrolysis.

\begin{tabular}{|c|c|c|c|c|c|}
\hline $\begin{array}{l}\text { Solid } \\
\text { loading }\end{array}$ & & $\begin{array}{l}\text { ar concentrat } \\
\qquad(\mathrm{g} / \mathrm{L})\end{array}$ & & & $\begin{array}{l}\text { Yield } \\
(\%)\end{array}$ \\
\hline & Glucose & Xylose & Cellibose & Glucose & Xylose \\
\hline $2 \mathrm{~B}$ & $9.9 \pm 0.36$ & $2.01 \pm 0.83$ & $1.28 \pm 0.24$ & $94.53 \pm 0.91$ & $58.4 \pm 6.8$ \\
\hline $20 \mathrm{~B}$ & $114.83 \pm 1.66$ & $15.40 \pm 0.23$ & $20.46 \pm 0.59$ & $83.67 \pm 1.39$ & $64.83 \pm 0.98$ \\
\hline $20 \mathrm{FE}$ & $111.74 \pm 1.88$ & $14.49 \pm 0.22$ & $20.61 \pm 0.27$ & $81.88 \pm 1.33$ & $60.97 \pm 0.91$ \\
\hline $10 \mathrm{~B}$ & $49.53 \pm 2.78$ & $9.25 \pm 4.45$ & $6.95 \pm 0.89$ & $86.17 \pm 5.65$ & $45.47 \pm 0.19$ \\
\hline $5 \mathrm{~B}$ & $25.95 \pm 1.86$ & $3.44 \pm 1.2$ & $3.71 \pm 0.95$ & $90.35 \pm 6.23$ & $30.98 \pm 9.23$ \\
\hline
\end{tabular}

B: Bach solid loading, FB: Fed-batch solid loading every 12 hours along with fed-batch enzyme loading.

\subsection{Fermentation}

\subsubsection{Effects of initial pH on B. licheniformis growth and acetoin production}

Four $\mathrm{pH}$ levels $(5,5.5,6$, and 6.5$)$ were tested at $30^{\circ} \mathrm{C}$ using $\mathrm{LB}$ media containing $50 \mathrm{~g} / \mathrm{L}$ glucose concentration. It was found that $B$. licheniformis can grow better and produce relatively high amount of acetoin $(18.87 \mathrm{~g} / \mathrm{L})$ at the initial of $\mathrm{pH}$ of 6 (Figure 4.4 ). The strain consumed all the glucose in the media and gave the acetoin yields of 0.36-0.38 $\mathrm{g} / \mathrm{g}$ across all the $\mathrm{pH}$ (Table 4.3), correpsoding to $73-78 \%$ of the theoretical yield $(0.49 \mathrm{~g} / \mathrm{g})$. As presented in Table 4.3 and Figure 4.3, the initial $\mathrm{pH}$ of 6 gave the highest $\mathrm{OD}$, acetoin concentration, and acetoin yield of $6.89,18.87$ $\mathrm{g} / \mathrm{L}$, and $0.377 \mathrm{~g} / \mathrm{g}$ respectively, along with $100 \%$ glucose consumption at the end of fermentation. Perego and coworker also reported that initial $\mathrm{pH}$ of 6 was prefered by another species of $B$. licheniformis (Bacillus licheniformis NCIMB8059) for micriobal growth and acetoin production (Perego, Converti et al. 2003). 
Table 4.3 Effects of initial $\mathrm{pH}$ of fermentation media on acetoin yield and glucose consumption.

\begin{tabular}{cccc}
\hline $\mathbf{p H}_{\mathbf{i}}$ & $\mathbf{p H}_{\mathbf{f}}$ & $\begin{array}{c}\text { Glucose consumption } \\
(\boldsymbol{\%})\end{array}$ & $\begin{array}{c}\text { Acetoin yield } \\
(\mathbf{g} / \mathbf{g})\end{array}$ \\
\hline 5 & 5.6 & 100 & $0.357 \pm 0.005$ \\
5.5 & 5.78 & 100 & $0.355 \pm 0.01$ \\
6 & 5.5 & 100 & $0.377 \pm 0.007$ \\
6.5 & 6.26 & 100 & $0.376 \pm 0.001$ \\
\hline
\end{tabular}

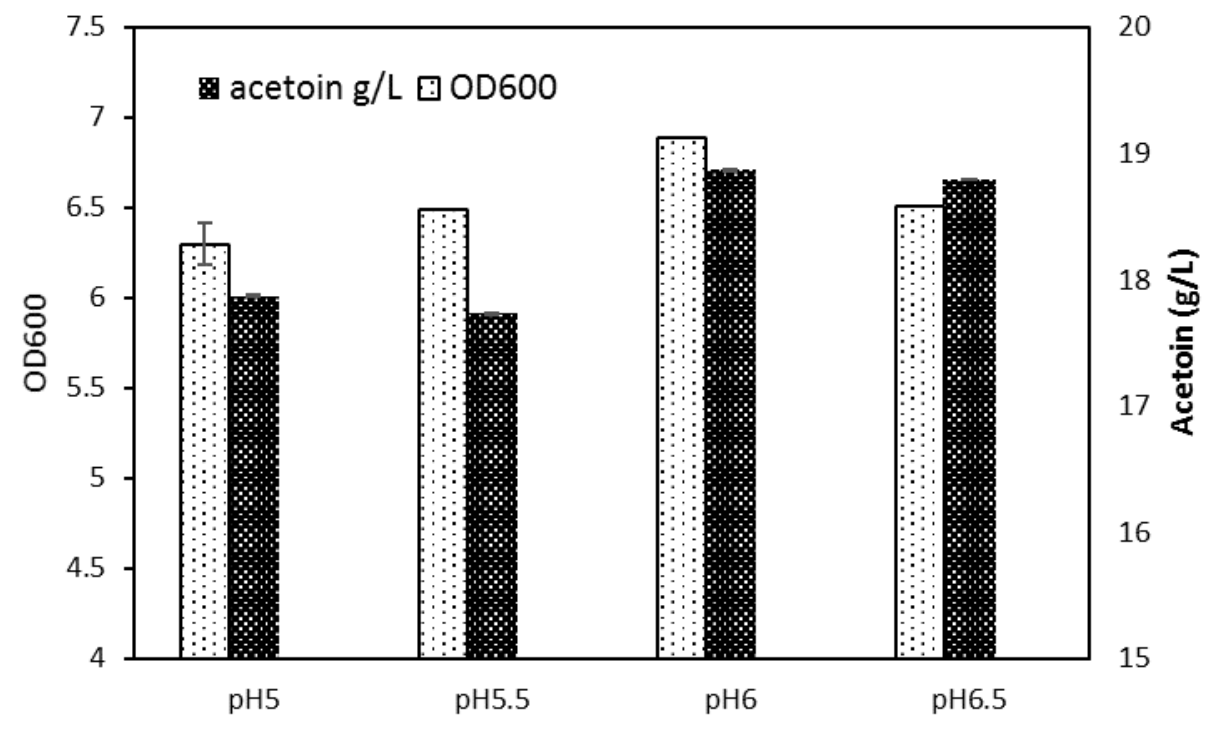

Figure 4.4 Effects of initial pH on B. licheniformis growth and acetoin production.

\subsubsection{Effects of temperature on B. licheniformis growth and acetoin production}

At the optimum initial $\mathrm{pH}$, the effects of fermentation temperature on bacteria growth and acetoin production were investigated at 30 , and $45^{\circ} \mathrm{C}$. One of the reasons to test temperature effect was to find the optimal temperature for conducing SSF which combines enzymatic hydrolysis and fermenation in one stage. Since the typical temperature for enzymatic hydrolysis is $50^{\circ} \mathrm{C}$, such 
temperature was also tested and found to be detrimental to cell growth. Comparing 30 and $45^{\circ} \mathrm{C}$, the former one appeared to be more suitable for cell growth and acetoin production (Figure 4.5). The yields of acetoin was also higher at $30^{\circ} \mathrm{C}$ althouth glucose was depleted at both temperatures (Table 4.4). Therefore, $30^{\circ} \mathrm{C}$ was selected for both SSF and SHF reported in Subsection 4.3.3.

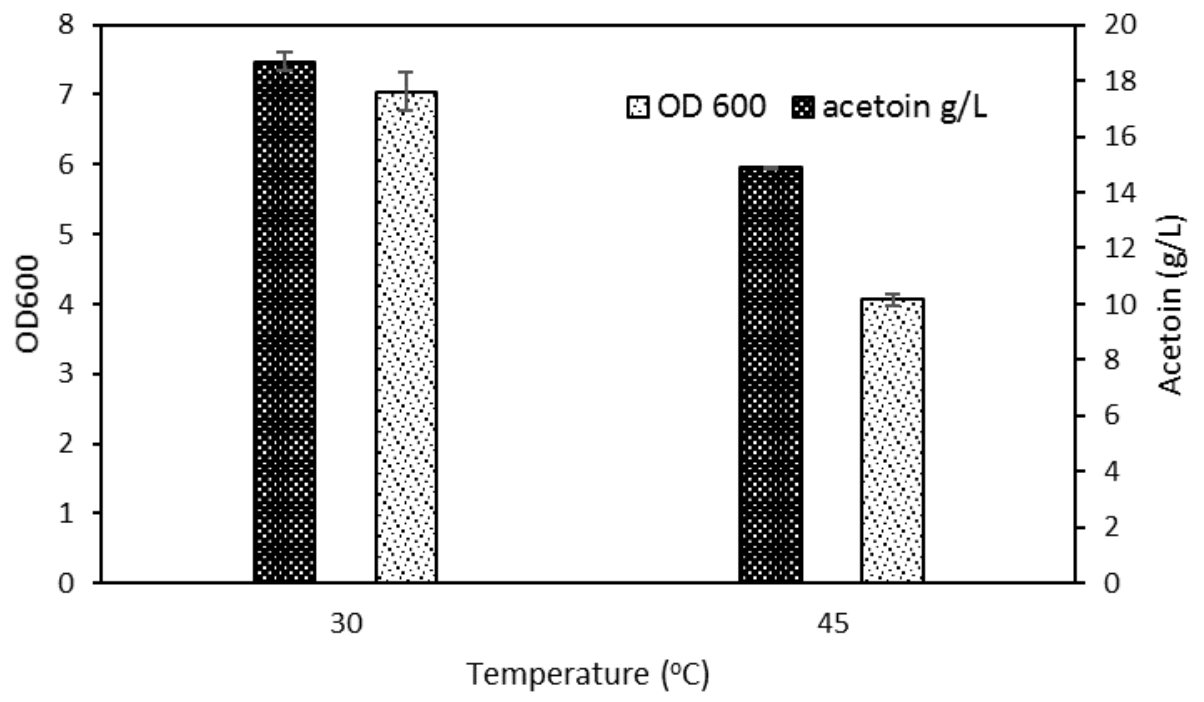

Figure 4.5 Effects of fermentation temperature on B. licheniformis growth and acetoin production.

Table 4.4 Effect of fermentation temperature on acetoin yield and glucose consumption.

\begin{tabular}{ccccc}
\hline $\begin{array}{c}\text { Temperature } \\
\left({ }^{\circ} \mathbf{C}\right)\end{array}$ & $\mathbf{p H}_{\mathbf{i}}$ & $\mathbf{p H}_{\mathbf{f}}$ & $\begin{array}{c}\text { Glucose } \\
\text { consumption }(\%)\end{array}$ & $\begin{array}{c}\text { Acetoin yield } \\
(\mathbf{g} / \mathbf{g})\end{array}$ \\
\hline 30 & 6 & 5.5 & 100 & $0.377 \pm 0.007$ \\
45 & 6 & 5.9 & 100 & $0.310 \pm 0.012$ \\
\hline
\end{tabular}




\subsubsection{Effects of initial glucose concentration on the main product distribution}

B. licheniformis has been reported to produce either acetoin or 2,3-butanediol as the dominant product depending on the culture conditions. We tested two initial sugar concentrations (50 and $80 \mathrm{~g} / \mathrm{L}$ ) for $48 \mathrm{~h}$ fermentation and found that the initial sugar concentration affected the production distribution rather than $\mathrm{pH}$ and tempreture as discussed above. When the initial glucose concentration was $50 \mathrm{~g} / \mathrm{L}$, acetoin was produced as the dominant product while 2,3-butanediol was minor (Figure 4.6a). The increase of initial glucose concentration from 50 to $80 \mathrm{~g} / \mathrm{L}$ led to increased 2,3-butanedoil as revealed by HPLC chromatograph ( Figure 4.6b). In addition, glucose was not completely consumed at such a high level. No significant amounts of other by-products, such as acetic acid and lactic acid, were detected in the fermneation broth for both cases. The selective production of acetoin and 2,3-butanediol as regulated by initial sugar concentration and other yetto-be-tested factors is important for downstream processing as no or little presence of undesired metabolites can simplify of downstream processing and thus save the associated cost. 
(a)

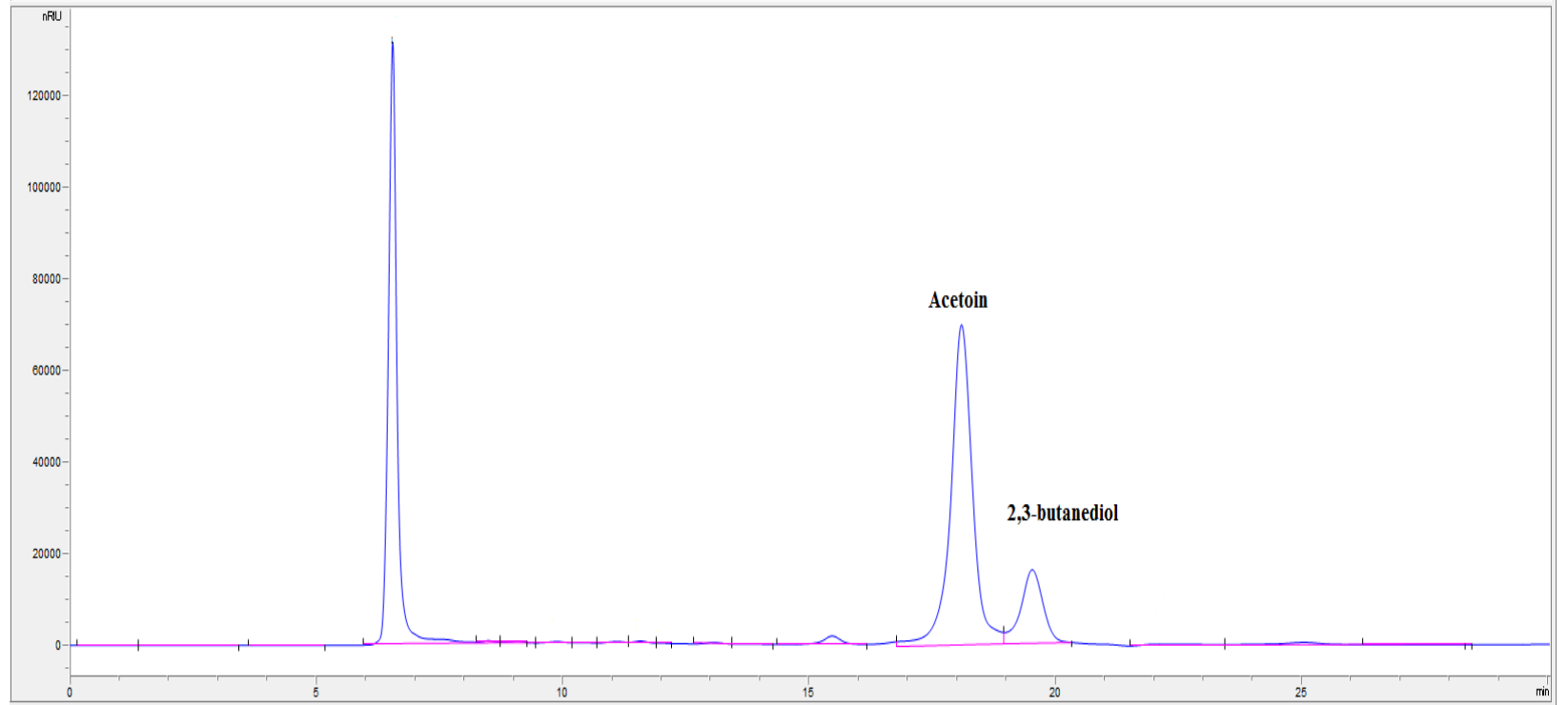

(b)

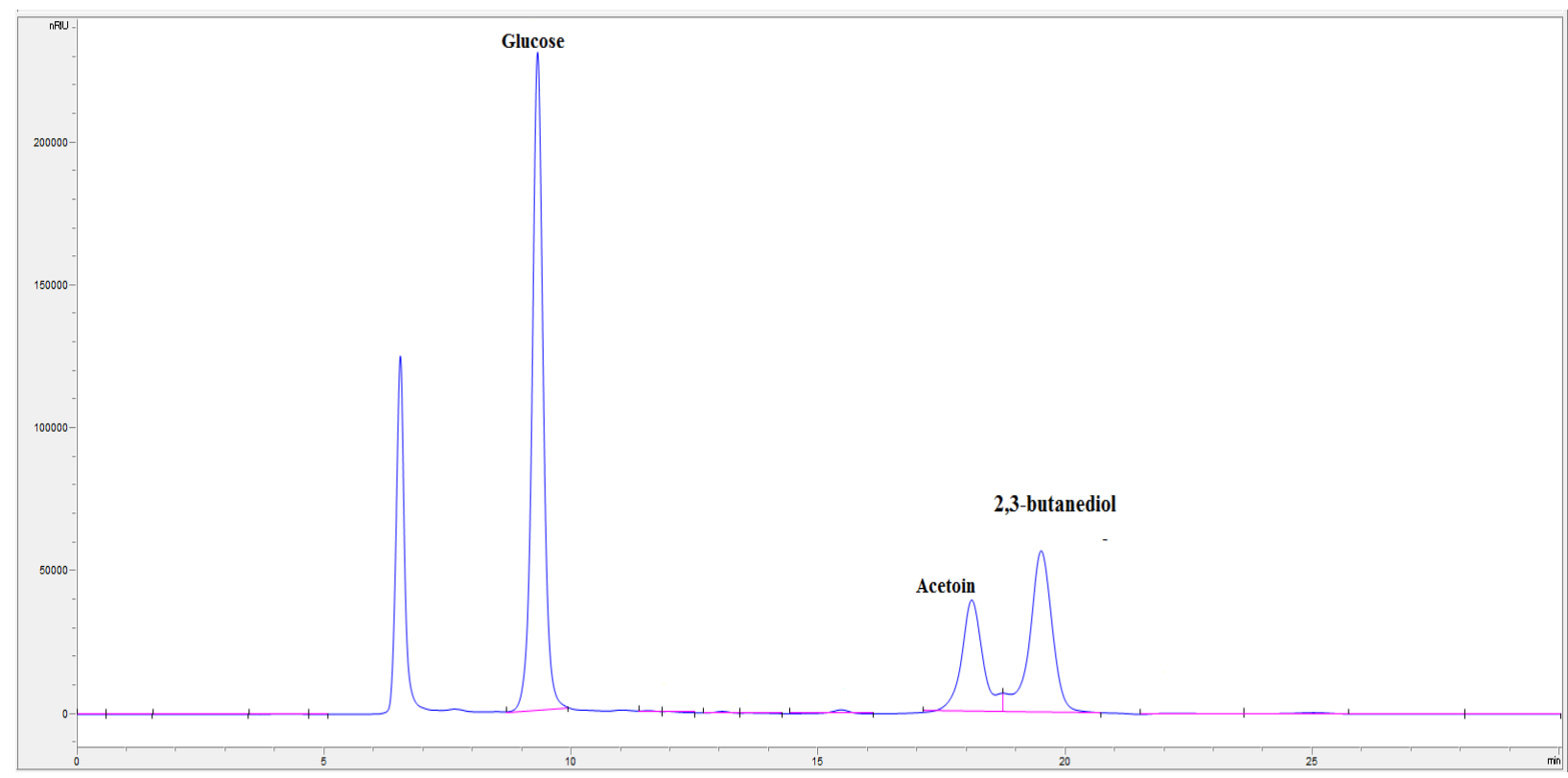

Figure 4.6 Main production distribution in response to initial glucose concentration: (a) $50 \mathrm{~g} / \mathrm{L}$ initial glucose concentration, and (b) $80 \mathrm{~g} / \mathrm{L}$ initial glucose concentration 


\subsubsection{Acetoin fermenation using pretreated switchgrass}

Two approaches, SHF and SSF, were used to test the acetoin production using pretreated biomass. The hydrolysate obtained from the high solid enzymatic hydrolysis as discussed in Subsection 4.2 was used for SHF. The tests were conducted at $30^{\circ} \mathrm{C}$ and $\mathrm{pH}$ of 6.0 with the initial sugar concentration adjusted to approximately $50 \mathrm{~g} / \mathrm{L}$. For SSF, the pretreated solids were loaded at $10 \mathrm{wt} \%$, corresponding to a theoretical glucose concentration approximately at $50 \mathrm{~g} / \mathrm{L}$. Cellulase and hemicellulase were loaded at 20 and $2 \mathrm{mg}$ protein/g solid, respectively, at the beginning of fermentation. The fermentation condition for SSF was $30^{\circ} \mathrm{C}$ and $\mathrm{pH}$ of 6.0 for $48 \mathrm{~h}$. The control was set along with each one using pure glucose as the carbon source. As depicted in Figure 4.8, the strain was not able to grow in the obtained hydrolysate and consume the glucose compared with control. The severely inhibited cell growth could be due to inhibitory compounds, such as lignin-derived compounds and organic acids, which were released during the hydrolysis of pretreated switchgrass. The way to process pretreatment slurry, especially washing the pretreated solids with water only, may not be able to remove all the lginin solublized from pretreatment. In some cases, lignin may be redeposited as peudo-lignin into the pretreated solids, which was revealed by increased ligin content compared to that of raw switchgrass.

Since the enzymatic hydrolysate of the pretreated solids had high toxicity to $B$. licheniformis, the dexotification was needed to remove toxic/inhibitory compounds from the hydrolystate. Overliming (OL), thanks to its high efficiency and little sugar loss, was widely adopted for detoxification of pretreatment slurry and enzymatic hydrolysate. We also used this method at mild condition $\left(30^{\circ} \mathrm{C}\right.$ and 1 hour) for detoxifying the hydrolysate of the pretreated solids, and found that this method was working as expected. HPLC results indicated that the overliming 
caused very minor sugar loss, only $2.3 \%, 2 \%$, and $9.8 \%$ for glucose, xylose, and cellobiose, respectively (Figure 4.7).

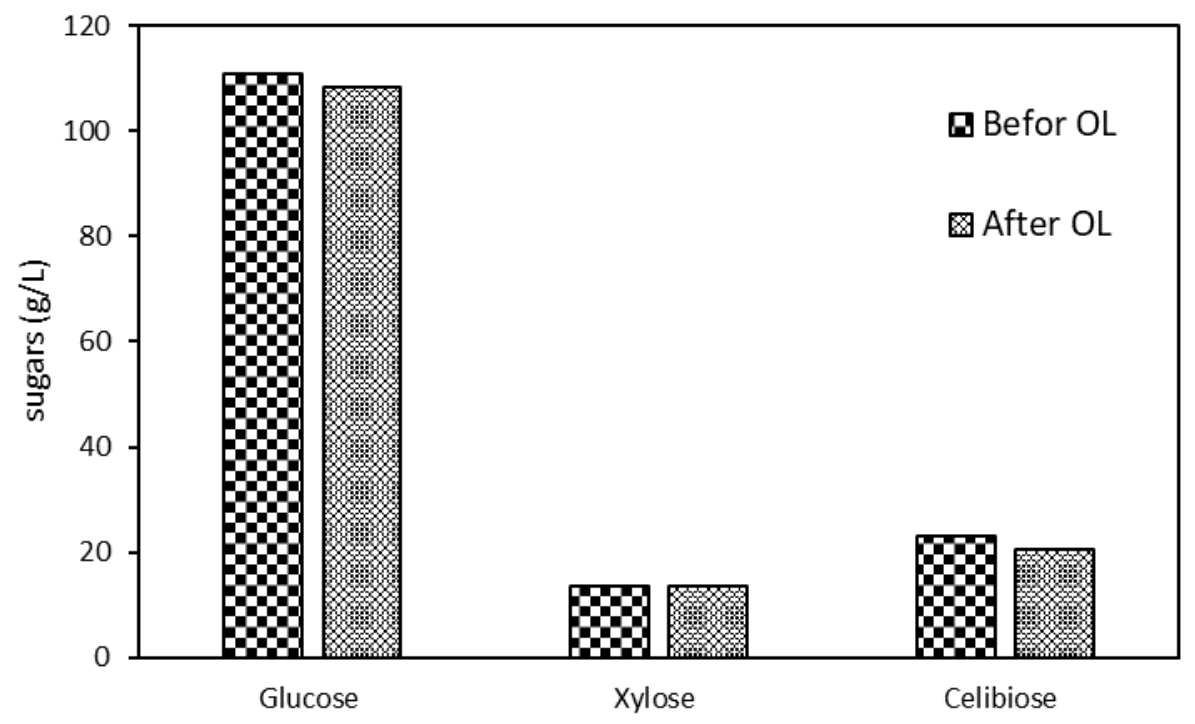

Figure 4.7 The effect of overliming on sugar concentration.

The fermentation tests showed that the srtain was able to could grow in fermentation media containing detoxified hydrolysate by overliming. Acetoin titers and yield were of $19.6 \mathrm{~g} / \mathrm{L}$ and $0.39 \mathrm{~g} / \mathrm{g}$, respectively, which is close to those of control (Figure 4.9). Similar to SHF using undetoxifed hydrolysate, no acetoin production was observed in SSF, which indicated that $B$. licheniformis was severely inhibited although it was impossible to directly detect OD. The other methods, like colony forming, can be used to confirm the cell growth. After culture the SSF and control in LB agar plates, it found that no growth appeared in SSF plates compared with obviously growth for control samples (Figure 4.10). The plate culture test confirmed the HPLC resuts. In addition, glucose was detected at about $20 \mathrm{~g} / \mathrm{L}$ at the end of SSF (48 hours), which was enzymatic hydrolyzed from the pretreated biomass. Most likely glucose was not comsumed at all by the strain as any acetoin was produced throughout SSF. Based on the above results it can be inferred that the 
enzymatic hydrolysis of pretreated switchgrass during SSF led to the release of toxic compounds into the fermenation media, which in turn severely discrupted cell growth and metabolism.

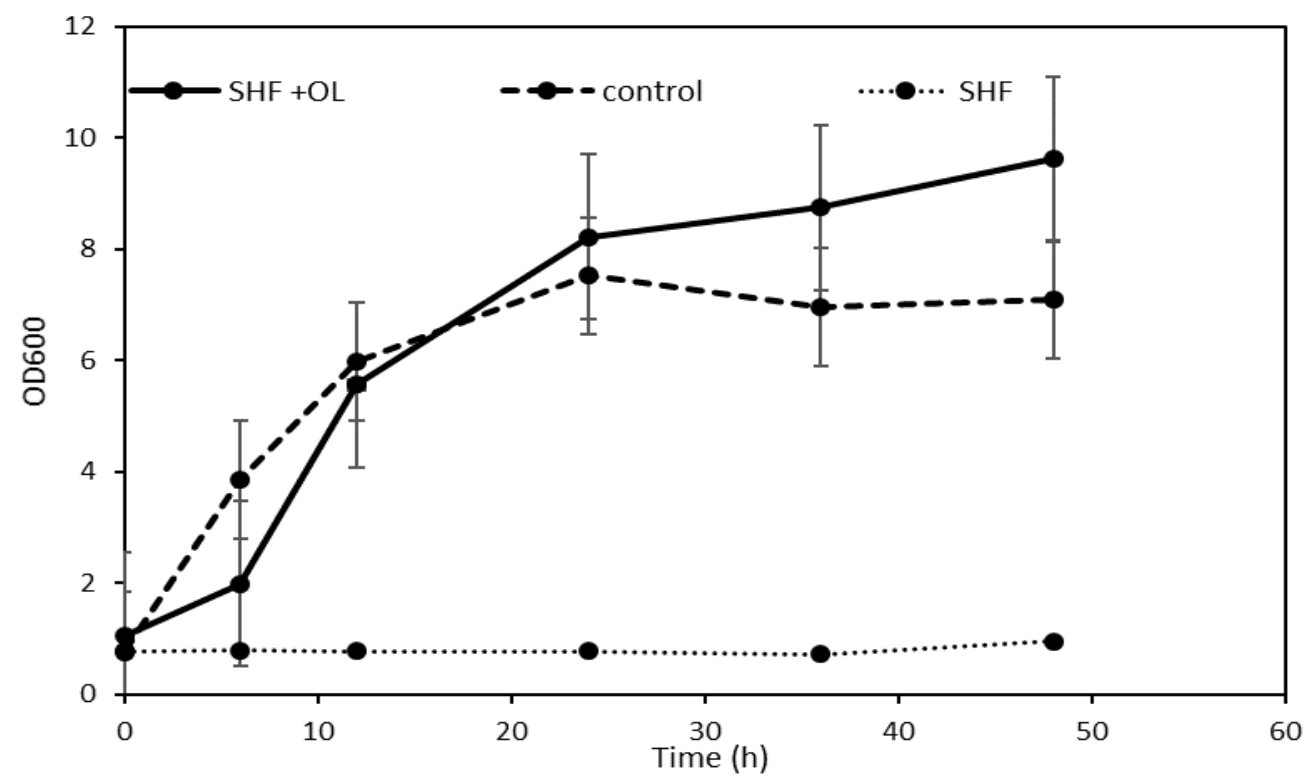

Figure 4.8 Growth of $B$. licheniformis in fermentation media containing pure or biomass hydrolysate.

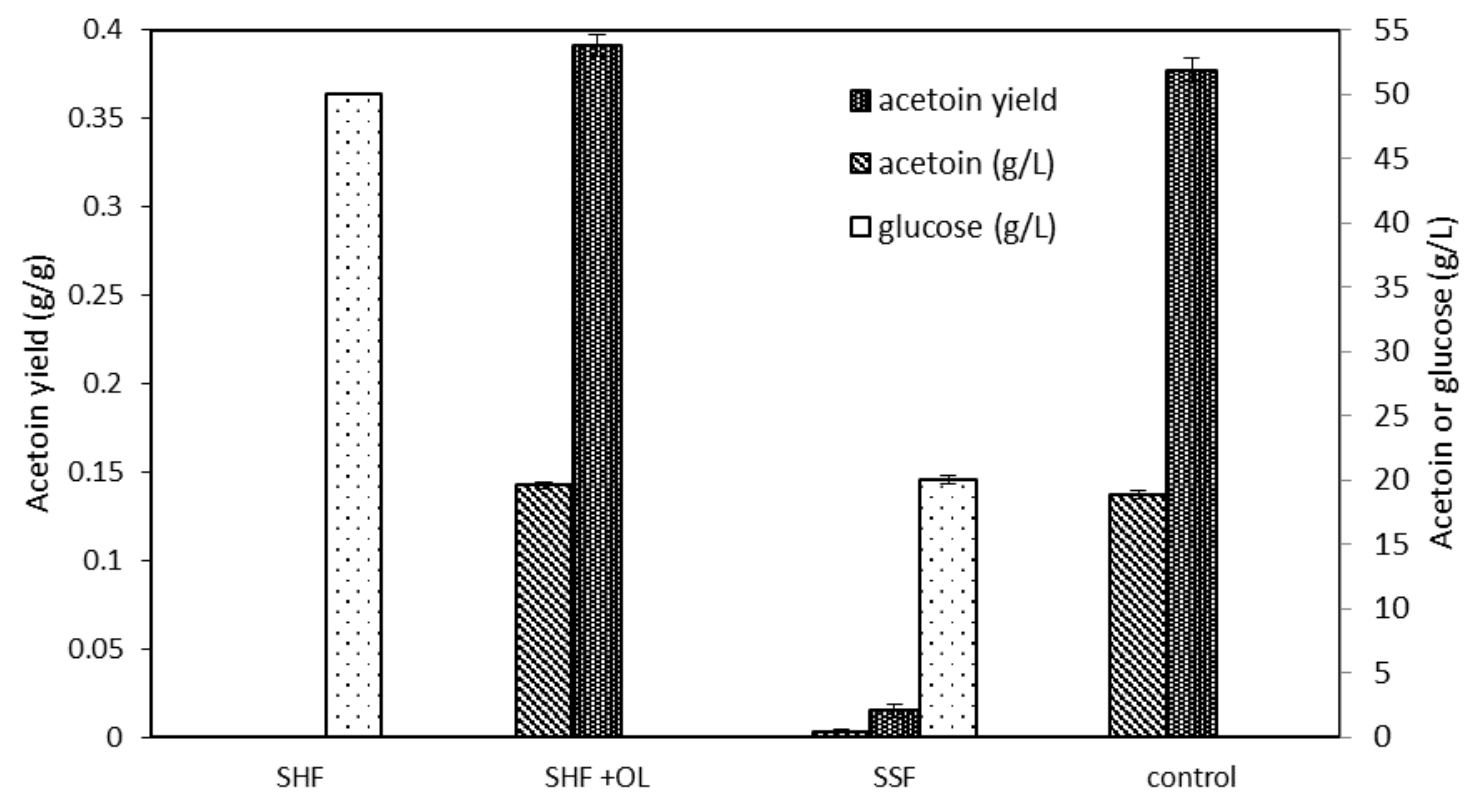

Figure 4.9 Acetoin production and glucose consumption by $B$. licheniformis using pretreated biomass. 


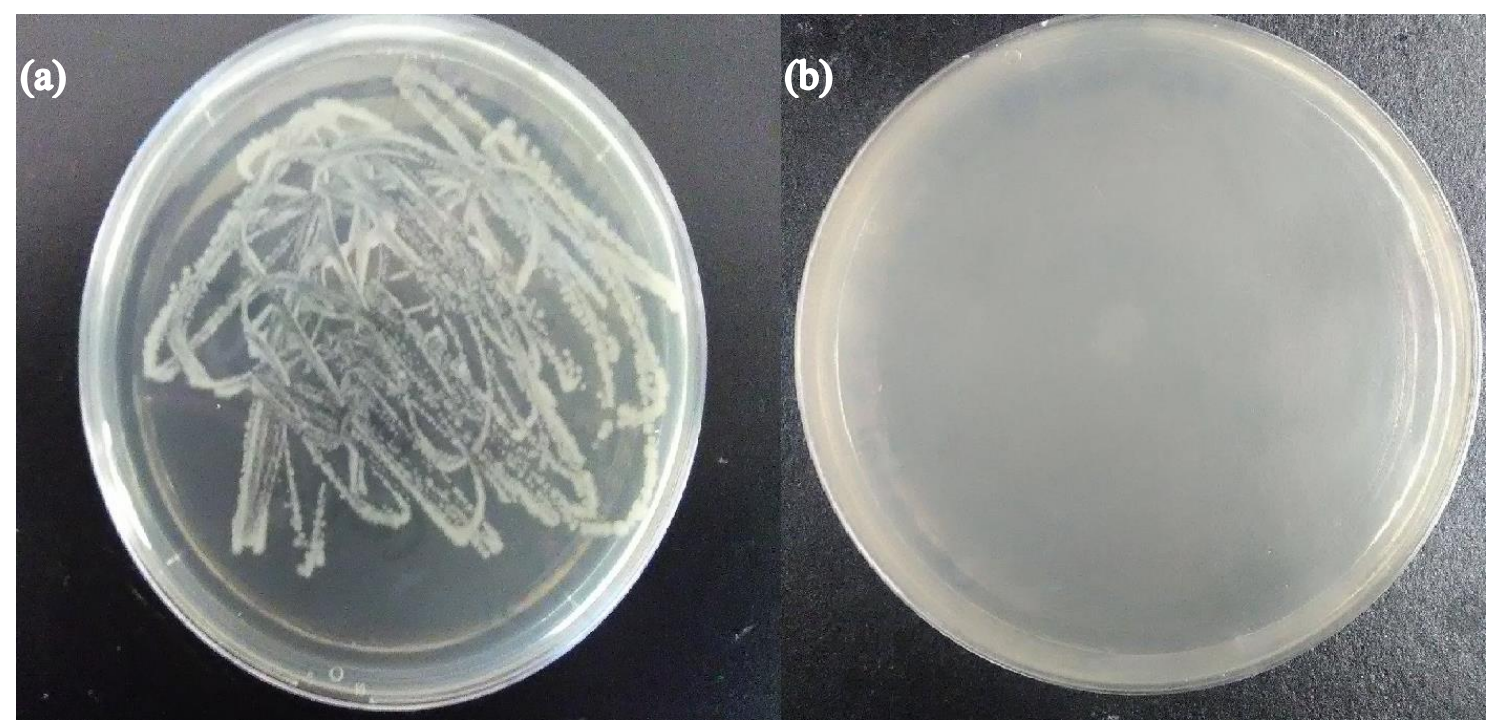

Figure 4.10 Growth of B. licheniformis in (a) control and (b) SSF. 


\section{Chapter 5}

\section{Conclusion and Future Work}

In this study, multiple DESs were synthesized by mixing $\mathrm{ChCl}$ and different hydrogen bond donor groups and applied in switchgrass pretreatment. Among the tested DESs, Ch-I pretreatment led to the highest amount of lignin removal (41\%), while Ch-FA pretreatment was most effective for xylan removal. In terms of cellulose digestibility, Ch-LA-AA pretreated switchgrass gave the highest glucose yield followed by Ch-FA pretretated switchgrass. Thus, Ch-FA and Ch-LA-AA standed out as the best performing DESs among the tested ones.

For high solid loading enzymatic hydrolysis of Ch-LA-AA pretreated switchgrass, no significant difference in glucose production was observed between batch solid loading and fedbatch solid loading to obtaina total of $20 \%$ solid loading. The glucose titers was correlated to solid loading while the glucose yields were decreased with an increase in solid loadings. The hydrolysate obtained from $20 \%$ batch solid loading was used for acetoin fermenation via SHF.

Acetoin fermenation using prereated biomass was conducted via both SHF and SSF. The above prepared hydrolysate was used as the carbon source for SHF, while the Ch-LA-AA pretreated switchgrasss was used for SSF. Either fermenation was conducted at $30^{\circ} \mathrm{C}$ with an agitation rate of $200 \mathrm{rpm}$ for $48 \mathrm{~h}$. The initial $\mathrm{pH}$ of 6 was for both SHF and SSF. The biomass hydrolysate was shown to be toxic to the acetoin-producing strain B. licheniformis as this strain was unable to grow and produce acetoin using such undetoxified hydrosate. This is due to the presence of inhibitory compounds released from the pretreated biomass via enzymatic hydrolsis. Overliming detoxification proved to be effective for removing possible toxic compounds in the hydrolysate with no significant sugar loss. As a result, B. licheniformis sucessfully used the detoxifed hydrolysate to produce $19.6 \mathrm{~g} / \mathrm{L}$ acetoin with the yield of $0.391 \mathrm{~g} / \mathrm{g}$, which was 
comparable to the acetoin fermnentation using pure glucuse at a very similar level. For SSF, similar to SHF using undetoxified hydrolysate, the strain failed to produce acetoin largely due to the release of toxic components from the pretreated switchgrass via enzymatic hydrolysis of SSF. These results indicated that detoxification appeared to be necessary to remove inhibitory compounds released from the pretreated switchgrass.

Future work will be focused on optimizing the pretreatment of the best-performing DESs and increasing acetoin production using real pretreated switchgrass as the carbon source. By optimizing the pretreatment process, the formation of inhibitory compounds could be minimized and the sugar yields could be maximized for switchgrass pretreated at mild condtions. The possible strategies for increassingacetoin production are: (1) optimizing fermentation media by studing the effect of different nitrogen source; (2) testing different fermentation modes; (3) studying the effect of agitation speed; and (4) gaining a better understanding of metabolic flux and metabolite distribution upon the change in fermentation conditions. 


\section{REFERENCES}

Abbott, A. P., J. C. Barron, K. S. Ryder and D. Wilson (2007). "Eutectic-Based Ionic Liquids with Metal-Containing Anions and Cations." Chemistry-A European Journal 13(22): 6495-6501.

Abbott, A. P., D. Boothby, G. Capper, D. L. Davies and R. K. Rasheed (2004). "Deep eutectic solvents formed between choline chloride and carboxylic acids: versatile alternatives to ionic liquids." Journal of the American Chemical Society 126(29): 9142-9147.

Alonso, D. M., J. Q. Bond and J. A. Dumesic (2010). "Catalytic conversion of biomass to biofuels." Green Chemistry 12(9): 1493-1513.

Alvira, P., E. Tomás-Pejó, M. Ballesteros and M. Negro (2010). "Pretreatment technologies for an efficient bioethanol production process based on enzymatic hydrolysis: a review." Bioresource technology 101(13): 4851-4861.

Bajpai, P. (2016). Structure of Lignocellulosic Biomass. Pretreatment of Lignocellulosic Biomass for Biofuel Production, Springer: 7-12.

Brodeur, G., E. Yau, K. Badal, J. Collier, K. Ramachandran and S. Ramakrishnan (2011). "Chemical and physicochemical pretreatment of lignocellulosic biomass: a review." Enzyme research 2011.

Cantarella, M., L. Cantarella, A. Gallifuoco, A. Spera and F. Alfani (2004). "Comparison of different detoxification methods for steam-exploded poplar wood as a substrate for the bioproduction of ethanol in SHF and SSF." Process Biochemistry 39(11): 1533-1542.

Cara, C., E. Ruiz, J. M. Oliva, F. Sáez and E. Castro (2008). "Conversion of olive tree biomass into fermentable sugars by dilute acid pretreatment and enzymatic saccharification." Bioresource technology 99(6): 1869-1876.

Chandel, A. K., O. V. Singh and S. S. da Silva (2011). Detoxification of lignocellulosic hydrolysates for improved bioethanol production, INTECH Open Access Publisher.

Chen, H. Z. and Z. H. Liu (2016). "Enzymatic hydrolysis of lignocellulosic biomass from low to high solids loading." Engineering in Life Sciences.

Dai, Y., J. van Spronsen, G.-J. Witkamp, R. Verpoorte and Y. H. Choi (2013). "Natural deep eutectic solvents as new potential media for green technology." Analytica chimica acta 766: 61-68.

Florindo, C., F. Oliveira, L. Rebelo, A. M. Fernandes and I. Marrucho (2014). "Insights into the synthesis and properties of deep eutectic solvents based on cholinium chloride and carboxylic acids." ACS Sustainable Chemistry \& Engineering 2(10): 2416-2425.

Francisco, M., A. van den Bruinhorst and M. C. Kroon (2012). "New natural and renewable low transition temperature mixtures (LTTMs): screening as solvents for lignocellulosic biomass processing." Green Chemistry 14(8): 2153-2157.

Francisco, M., A. van den Bruinhorst and M. C. Kroon (2013). "Low-transition-temperature mixtures (LTTMs): A new generation of designer solvents." Angewandte Chemie international edition 52(11): 3074-3085.

Fu, D., G. Mazza and Y. Tamaki (2010). "Lignin extraction from straw by ionic liquids and enzymatic hydrolysis of the cellulosic residues." Journal of agricultural and food chemistry 58(5): 2915-2922.

Galbe, M. and G. Zacchi (2002). "A review of the production of ethanol from softwood." Applied microbiology and biotechnology 59(6): 618-628.

Gírio, F. M., C. Fonseca, F. Carvalheiro, L. C. Duarte, S. Marques and R. Bogel-Łukasik (2010). "Hemicelluloses for fuel ethanol: a review." Bioresource technology 101(13): 4775-4800. 
Gorke, J. T., F. Srienc and R. J. Kazlauskas (2008). "Hydrolase-catalyzed biotransformations in deep eutectic solvents." Chemical Communications(10): 1235-1237.

Jönsson, L. J., B. Alriksson and N.-O. Nilvebrant (2013). "Bioconversion of lignocellulose: inhibitors and detoxification." Biotechnology for biofuels 6(1): 16.

Jurchescu, I.-M., J. Hamann, X. Zhou, T. Ortmann, A. Kuenz, U. Prüße and S. Lang (2013). "Enhanced 2, 3-butanediol production in fed-batch cultures of free and immobilized Bacillus licheniformis DSM 8785." Applied microbiology and biotechnology 97(15): 6715-6723.

Kimon, K. S., E. L. Alan and D. W. O. Sinclair (2011). "Enhanced saccharification kinetics of sugarcane bagasse pretreated in 1-butyl-3-methylimidazolium chloride at high temperature and without complete dissolution." Bioresource technology 102(19): 93259329.

Kristensen, J. B., C. Felby and H. Jørgensen (2009). "Determining yields in high solids enzymatic hydrolysis of biomass." Applied biochemistry and biotechnology 156(1-3): 127-132.

Kumar, A. K., B. S. Parikh, E. Shah, L. Z. Liu and M. A. Cotta (2016). "Cellulosic ethanol production from green solvent-pretreated rice straw." Biocatalysis and Agricultural Biotechnology 7: 14-23.

Kumar, P., D. M. Barrett, M. J. Delwiche and P. Stroeve (2009). "Methods for pretreatment of lignocellulosic biomass for efficient hydrolysis and biofuel production." Industrial \& engineering chemistry research 48(8): 3713-3729.

Li, L., X. Wei, W. Yu, Z. Wen and S. Chen (2017). "Enhancement of acetoin production from Bacillus licheniformis by 2, 3-butanediol conversion strategy: Metabolic engineering and fermentation control." Process Biochemistry 57: 35-42.

Li, L., L. Zhang, K. Li, Y. Wang, C. Gao, B. Han, C. Ma and P. Xu (2013). "A newly isolated Bacillus licheniformis strain thermophilically produces 2, 3-butanediol, a platform and fuel bio-chemical." Biotechnology for biofuels 6(1): 123.

Li, M.-F., Y.-M. Fan, F. Xu, R.-C. Sun and X.-L. Zhang (2010). "Cold sodium hydroxide/urea based pretreatment of bamboo for bioethanol production: characterization of the cellulose rich fraction." Industrial Crops and Products 32(3): 551-559.

Limayem, A. and S. C. Ricke (2012). "Lignocellulosic biomass for bioethanol production: current perspectives, potential issues and future prospects." Progress in Energy and Combustion Science 38(4): 449-467.

Liu, Y., S. Zhang, Y.-C. Yong, Z. Ji, X. Ma, Z. Xu and S. Chen (2011). "Efficient production of acetoin by the newly isolated Bacillus licheniformis strain MEL09." Process Biochemistry 46(1): 390-394.

Millati, R., C. Niklasson and M. J. Taherzadeh (2002). "Effect of pH, time and temperature of overliming on detoxification of dilute-acid hydrolyzates for fermentation by Saccharomyces cerevisiae." Process Biochemistry 38(4): 515-522.

Modenbach, A. A. and S. E. Nokes (2012). "The use of high-solids loadings in biomass pretreatment—a review." Biotechnology and Bioengineering 109(6): 1430-1442.

Morrison, H. G., C. C. Sun and S. Neervannan (2009). "Characterization of thermal behavior of deep eutectic solvents and their potential as drug solubilization vehicles." International journal of pharmaceutics 378(1): 136-139. 
Mosier, N., C. Wyman, B. Dale, R. Elander, Y. Lee, M. Holtzapple and M. Ladisch (2005). "Features of promising technologies for pretreatment of lignocellulosic biomass." Bioresource technology 96(6): 673-686.

Murzin, D. Y. (2012). Chemical engineering for renewables conversion, Academic Press.

Mussatto, S. (2016). Biomass fractionation technologies for a lignocellulosic feedstock based biorefinery, Elsevier.

Mussatto, S. I. (2016). Biomass Fractionation Technologies for a Lignocellulosic Feedstock Based Biorefinery, ELSEVIER.

Mussatto, S. I. and I. C. Roberto (2004). "Alternatives for detoxification of diluted-acid lignocellulosic hydrolyzates for use in fermentative processes: a review." Bioresource technology 93(1): 1-10.

Nevoigt, E. (2008). "Progress in metabolic engineering of Saccharomyces cerevisiae." Microbiology and Molecular Biology Reviews 72(3): 379-412.

Nguyen, Q. A., M. P. Tucker, F. A. Keller, D. A. Beaty, K. M. Connors and F. P. Eddy (1999). "Dilute acid hydrolysis of softwoods." Applied biochemistry and biotechnology 77(1-3): 133-142.

Paiva, A., R. Craveiro, I. Aroso, M. Martins, R. L. Reis and A. R. C. Duarte (2014). "Natural deep eutectic solvents-solvents for the 21st century." ACS Sustainable Chemistry \& Engineering 2(5): 1063-1071.

Perego, P., A. Converti and M. Del Borghi (2003). "Effects of temperature, inoculum size and starch hydrolyzate concentration on butanediol production by Bacillus licheniformis." Bioresource Technology 89(2): 125-131.

Persson, P., J. Andersson, L. Gorton, S. Larsson, N.-O. Nilvebrant and L. J. Jönsson (2002). "Effect of different forms of alkali treatment on specific fermentation inhibitors and on the fermentability of lignocellulose hydrolysates for production of fuel ethanol." Journal of Agricultural and food chemistry 50(19): 5318-5325.

Prasad, A., M. Sotenko, T. Blenkinsopp and S. R. Coles (2016). "Life cycle assessment of lignocellulosic biomass pretreatment methods in biofuel production." The International Journal of Life Cycle Assessment 21(1): 44-50.

Procentese, A., E. Johnson, V. Orr, A. G. Campanile, J. A. Wood, A. Marzocchella and L. Rehmann (2015). "Deep eutectic solvent pretreatment and subsequent saccharification of corncob." Bioresource technology 192: 31-36.

Qi, G., Y. Kang, L. Li, A. Xiao, S. Zhang, Z. Wen, D. Xu and S. Chen (2014). "Deletion of meso-2, 3-butanediol dehydrogenase gene bud $\mathrm{C}$ for enhanced D-2, 3-butanediol production in Bacillus licheniformis." Biotechnology for biofuels 7(1): 16.

Roncal, T., S. Caballero, M. d. M. D. de Guereñu, I. Rincón, S. Prieto-Fernández and J. R. Ochoa-Gómez (2017). "Efficient production of acetoin by fermentation using the newly isolated mutant strain Lactococcus lactis subsp. lactis CML B4." Process Biochemistry.

Saha, B. C. (2003). "Hemicellulose bioconversion." Journal of Industrial Microbiology and Biotechnology 30(5): 279-291.

Sluiter, A., B. Hames, R. Ruiz, C. Scarlata, J. Sluiter, D. Templeton and D. Crocker (2008). "Determination of structural carbohydrates and lignin in biomass." Laboratory analytical procedure 1617.

Smith, E. L., A. P. Abbott and K. S. Ryder (2014). "Deep eutectic solvents (DESs) and their applications." Chemical reviews 114(21): 11060-11082. 
Stöcker, M. (2008). "Biofuels and biomass-to-liquid fuels in the biorefinery: Catalytic conversion of lignocellulosic biomass using porous materials." Angewandte Chemie International Edition 47(48): 9200-9211.

Sun, J.-A., L.-Y. Zhang, B. Rao, Y.-L. Shen and D.-Z. Wei (2012). "Enhanced acetoin production by Serratia marcescens H32 with expression of a water-forming NADH oxidase." Bioresource technology 119: 94-98.

Sun, J., L. Zhang, B. Rao, Y. Han, J. Chu, J. Zhu, Y. Shen and D. Wei (2012). "Enhanced acetoin production by Serratia marcescens H32 using statistical optimization and a twostage agitation speed control strategy." Biotechnology and bioprocess engineering 17(3): 598-605.

Sun, Y. and J. Cheng (2002). "Hydrolysis of lignocellulosic materials for ethanol production: a review." Bioresource technology 83(1): 1-11.

van Osch, D. J., L. J. Kollau, A. van den Bruinhorst, S. Asikainen, M. A. Rocha and M. C. Kroon (2017). "Ionic liquids and deep eutectic solvents for lignocellulosic biomass fractionation." Physical Chemistry Chemical Physics.

Van Zyl, C., B. A. Prior and J. C. Du Preez (1988). "Production of ethanol from sugar cane bagasse hemicellulose hydrolyzate byPichia stipitis." Applied Biochemistry and Biotechnology 17(1): 357-369.

Wahlström, R., J. Hiltunen, M. P. d. S. N. Sirkka, S. Vuoti and K. Kruus (2016). "Comparison of three deep eutectic solvents and 1-ethyl-3-methylimidazolium acetate in the pretreatment of lignocellulose: effect on enzyme stability, lignocellulose digestibility and one-pot hydrolysis." RSC Advances 6(72): 68100-68110.

Werpy, T., G. Petersen, A. Aden, J. Bozell, J. Holladay, J. White, A. Manheim, D. Eliot, L. Lasure and S. Jones (2004). Top value added chemicals from biomass. Volume 1-Results of screening for potential candidates from sugars and synthesis gas, DTIC Document.

Xiao, Z. and J. R. Lu (2014). "Strategies for enhancing fermentative production of acetoin: a review." Biotechnology advances 32(2): 492-503.

Xu, G.-C., J.-C. Ding, R.-Z. Han, J.-J. Dong and Y. Ni (2016). "Enhancing cellulose accessibility of corn stover by deep eutectic solvent pretreatment for butanol fermentation." Bioresource technology 203: 364-369.

$\mathrm{Xu}, \mathrm{H}$., S. Jia and J. Liu (2011). Production of acetoin by Bacillus subtilis TH-49. Consumer Electronics, Communications and Networks (CECNet), 2011 International Conference on, IEEE.

Xu, P., Z. Xiao, Y. Du and Z. Wei (2012). Acetoin high-yield Bacillus pumilus strain, Google Patents.

Zhang, C.-W., S.-Q. Xia and P.-S. Ma (2016). "Facile pretreatment of lignocellulosic biomass using deep eutectic solvents." Bioresource Technology 219: 1-5.

Zhang, Q., K. D. O. Vigier, S. Royer and F. Jérôme (2012). "Deep eutectic solvents: syntheses, properties and applications." Chemical Society Reviews 41(21): 7108-7146.

Zhang, X., T.-w. Yang, Q. Lin, M.-j. Xu, H.-f. Xia, Z.-h. Xu, H.-z. Li and Z.-m. Rao (2011). "Isolation and identification of an acetoin high production bacterium that can reverse transform 2, 3-butanediol to acetoin at the decline phase of fermentation." World Journal of Microbiology and Biotechnology 27(12): 2785-2790.

Zhao, H. and G. A. Baker (2013). "Ionic liquids and deep eutectic solvents for biodiesel synthesis: a review." Journal of Chemical Technology and Biotechnology 88(1): 3-12. 